CAMINHA, Uinie; NORÕES, Mariane. Mercado de saúde suplementar no Brasil e a seleção adversa: uma análise econômica a partir da política de controle de preços dos planos individuais. Revista Eletrônica Direito e Política, Programa de Pós-Graduação Stricto Sensu em Ciência Jurídica da UNIVALI, Itajaí, v.13, n.3, $3^{\circ}$ quadrimestre de 2018. Disponível em: www.univali.br/direitoepolitica - ISSN 1980-7791

\title{
MERCADO DE SAÚDE SUPLEMENTAR NO BRASIL E A SELEÇÃO ADVERSA: UMA ANÁLISE ECONÔMICA A PARTIR DA POLÍTICA DE CONTROLE DE PREÇOS DOS PLANOS INDIVIDUAIS ${ }^{1}$
}

\author{
SUPPLEMENTARY HEALTH MARKET IN BRAZIL AND ADVERSE SELECTION: AN \\ ECONOMIC ANALYSIS BASED ON THE PRICE CONTROL POLICY OF INDIVIDUAL
}

PLANS

\author{
Uinie Caminha² \\ Mariane Norões ${ }^{3}$
}

SUMÁRIO: Introdução; 1 o mercado de saúde suplementar no Brasil; 2 Política de controle de preços dos planos individuais de assistência à saúde; 3 Análise econômica da política de controle de preços dos planos individuais e a seleção adversa no mercado de saúde suplementar; Considerações finais; Referências das fontes citadas.

\section{RESUMO}

Este artigo objetiva analisar como a política de controle de preços dos planos de saúde na modalidade individual ou familiar gera seleção adversa no mercado de saúde suplementar do Brasil. A metodologia utilizada foi do tipo documentalbibliográfico, com pesquisa pura de abordagem qualitativa, descritiva e exploratória. A Agência Nacional de Saúde Suplementar regulou os critérios de reajuste de preços por mudança de faixa etária, por meio da Resolução Normativa no 63/2003. Esta Resolução estabeleceu dez faixas etárias, sendo o último reajuste aos 59 anos ou mais. Todavia, o Instituto Brasileiro de Geografia e Estatística alerta para um declínio na fecundidade e um aumento da população idosa. Conclui-se, pelo estudo realizado, que a regulação estatal dos preços dos planos de saúde gera um aumento no custo de transação dos planos individuais de assistência privada à saúde $e$, por conseguinte, o fenômeno da seleção adversa no mercado de saúde suplementar.

Palavras-chave: Consumidores; Mercado de saúde suplementar; Plano de saúde; Reajuste de preço; Seleção Adversa.

\footnotetext{
${ }^{1} \mathrm{O}$ presente artigo é fruto de pesquisa realizada com apoio da Fundação Cearense de Apoio ao Desenvolvimento Científico e Tecnológico (FUNCAP), com bolsa de formação acadêmica na modalidade mestrado acadêmico - Edital no 56/2016 da Universidade de Fortaleza.

2 Doutora em Direito Comercial pela Faculdade de Direito da Universidade de São Paulo. Professora titular do Programa de Pós-Graduação em Direito Constitucional (Mestrado e Doutorado) da Universidade de Fortaleza. Professora Adjunta da Universidade Federal do Ceará. Advogada. Fortaleza/CE, Brasil. E-mail: ucaminha@gmail.com.

3 Mestranda em Direito Constitucional pelo Programa de Pós-Graduação em Direito Constitucional da Universidade de Fortaleza. Pesquisadora-bolsista da Fundação Cearense de Apoio ao Desenvolvimento Científico e Tecnológico (FUNCAP). Advogada. Fortaleza/CE, Brasil. E-mail: marianenoroes@hotmail.com.
} 
CAMINHA, Uinie; NORÕES, Mariane. Mercado de saúde suplementar no Brasil e a seleção adversa: uma análise econômica a partir da política de controle de preços dos planos individuais. Revista Eletrônica Direito e Política, Programa de Pós-Graduação Stricto Sensu em Ciência Jurídica da UNIVALI, Itajaí, v.13, n.3, $3^{\circ}$ quadrimestre de 2018. Disponível em: www.univali.br/direitoepolitica - ISSN 1980-7791

\section{Abstract}

This article aims to analyze how the price control policy of health plans in the individual or family modality generates adverse selection in the supplementary health market in Brazil. The methodology used was of the documentarybibliographic type, with pure research of qualitative, descriptive and exploratory approach. The National Agency of Supplementary Health regulated the price adjustment criteria for changing age, by means of Normative Resolution no. $63 / 2003$. This Resolution established ten age groups, the last adjustment being at age 59 or over. However, the Brazilian Institute of Geography and Statistics warns of a decline in fertility and an increase in the elderly population. It is concluded from the study that the state regulation of health insurance prices generates an increase in the transaction cost of individual private health care plans and, consequently, the phenomenon of adverse selection in the supplementary health market.

Key-words: Consumers; Supplementary health market; Health insurance; Price adjustment; Adverse Selection.

\section{INTRODUÇÃo}

A saúde e as ações e serviços dela decorrentes são regidos pelos artigos 196 a 200 da Constituição da República Federativa do Brasil de 1988 e por um conjunto de leis, notadamente, a Lei no 8.080/90 (Lei Orgânica da Saúde), a Lei no 9.656/98 (Lei dos Planos de Saúde) e as resoluções normativas da Agência Nacional de Saúde Suplementar - ANS.

A Constituição Federal de 1988, em seu artigo 196, prevê que a saúde é "direito de todos e dever do Estado", exigindo-se, para a sua efetivação, a adoção de políticas públicas de caráter preventivo e reparativo, bem como o dever de agir fornecendo a todas as pessoas prestações adequadas à promoção, proteção e recuperação da saúde, independente de contribuição à Seguridade Social ${ }^{4}$.

Todavia, os recursos públicos são escassos ${ }^{5}$ e os serviços e produtos médicohospitalares e odontológicos possuem um custo ${ }^{6}$. Por essas razões, as prestações

\footnotetext{
${ }^{4}$ BRASIL. Constituição da República Federativa do Brasil. Brasília: Senado Federal, 1988. Disponível em: <http://www.planalto.gov.br/ccivil_03/constituicao/constituicaocompilado.htm>. Acesso em: 25 out. 2017.

5 SARLET, Ingo Wolgang; SAAVEDRA, Giovani Agostini. Judicialização, reserva do possível e compliance na área da saúde. Revista de Direitos e Garantias Fundamentais, Vitória, v. 18, n. 1 , p. 257-282, jan./abr. 2017.
} 
CAMINHA, Uinie; NORÕES, Mariane. Mercado de saúde suplementar no Brasil e a seleção adversa: uma análise econômica a partir da política de controle de preços dos planos individuais. Revista Eletrônica Direito e Política, Programa de Pós-Graduação Stricto Sensu em Ciência Jurídica da UNIVALI, Itajaí, v.13, n.3, $3^{\circ}$ quadrimestre de 2018. Disponível em: www.univali.br/direitoepolitica - ISSN 1980-7791

de saúde requerem a definição de "prioridades"7 e a atuação da iniciativa privada na assistência à saúde, a qual foi autorizada pelos artigos 197 e 199, caput, da Constituição Federal de 1988.

Percebe-se, por oportuno, que, no Brasil, os serviços de saúde não são exclusivos da Administração Pública, sendo também livre à iniciativa privada8 . Contudo, nem por isso, referidos serviços deixam de ter natureza jurídica pública9 ${ }^{9}$. Ou seja, ainda que prestados por particular, os serviços de saúde são serviços públicos, denominados de serviços públicos não privativos ${ }^{10}$. Isto, porque podem ser prestados pelo setor privado independente de concessão, permissão ou autorização da Administração Pública e, também, porque foram delimitados pela própria Constituição como "dever do Estado" (artigo 196) e de "relevância pública" (artigo 197), resguardando ao Poder Público o dever de regulamentação, fiscalização e controle da atividade econômica e de assistência à saúde.

Com base na ordem jurídica vigente, a prestação de serviços pela iniciativa privada pode ser de duas formas: complementar e suplementar. A participação do ente privado na modalidade complementar se dá mediante contrato de direito público ou convênio junto ao Sistema Único de Saúde - SUS, e sob as diretrizes e financiamento deste ( 24 a 26 da Lei no 8.080/1990). Por sua vez, a saúde suplementar é aquela prestada pelo ente particular com custeio exclusivamente privado e sem qualquer vinculação com o SUS. O financiamento dos serviços de saúde suplementar pode ocorrer diretamente pelo usuário ou por meio de

6 BARROS, Pedro Pita. Economia da Saúde: conceitos contemporâneos. 3. ed. Coimbra: Almedina, 2016.

7 BARCELLOS, Ana Paula Gonçalves Pereira de et al. Direito à saúde e prioridades: introdução a um debate inevitável. Revista Direito GV, São Paulo, v. 13, n. 2, p. 457-483, maio-ago. 2017. Disponível em: <http://www.scielo.br/pdf/rdgv/v13n2/1808-2432-rdgv-13-02-0457.pdf>. Acesso em: 26 nov. 2017.

8 DI PIETRO, Maria Sylvia Zanella. Direito Administrativo. 26. ed. São Paulo: Atlas, 2013.

9 SANTOS, Lenir. A natureza jurídica pública dos serviços de saúde e o regime de complementaridade dos serviços privados à rede pública do Sistema Único de Saúde. Saúde debate, Rio de Janeiro, v. 39, n. 106, p. 815-829, jul-set, 2015. Disponível em: <http://www.scielo.br/pdf/sdeb/v39n106/0103-1104-sdeb-39-106-00815.pdf>. Acesso em: 26 nov. 2017.

10 GRAU, Eros Roberto. A ordem econômica na Constituição de 1988. 12. ed. São Paulo: Malheiros, 2007. 
CAMINHA, Uinie; NORÕES, Mariane. Mercado de saúde suplementar no Brasil e a seleção adversa: uma análise econômica a partir da política de controle de preços dos planos individuais. Revista Eletrônica Direito e Política, Programa de Pós-Graduação Stricto Sensu em Ciência Jurídica da UNIVALI, Itajaí, v.13, n.3, $3^{\circ}$ quadrimestre de 2018. Disponível em: www.univali.br/direitoepolitica - ISSN 1980-7791

contratação voluntária dos planos e seguros de saúde - individuais (ou familiares) e coletivos empresariais e por adesão -, que intermediam o pagamento dos serviços aos prestadores. Os planos de saúde estão sujeitos às normas da Lei no 9.656/91 e as normas das resoluções normativas da ANS.

Este estudo pretende fazer uma análise do mercado de saúde suplementar, que, segundo dados oficiais da ANS, é responsável pela cobertura de 36,33\% da população brasileira, ou seja, ela conta com 47,4 milhões de beneficiários de planos médico-hospitalares, distribuídos em 761 operadoras ativas no Brasil, e 23,1 milhões de beneficiários de planos exclusivamente odontológicos, em 396 operadoras $^{11}$. Com efeito, o sistema de saúde suplementar alivia financeiramente o SUS, uma vez que parte da população brasileira procura os serviços cobertos pelos planos ao invés dos serviços públicos.

Todavia, a ANS aponta para uma retração nesse mercado desde dezembro de 2015. Ressalte-se que, de dezembro de 2000 a dezembro de 2014, as taxas de crescimento do número de beneficiários em planos privados de assistência médico-hospitalar eram positivas ${ }^{12}$. Em dezembro de 2014, o segmento de saúde suplementar era representado por 875 operadoras médico-hospitalares, cujo Cadastro de Beneficiário registrou 50,4 milhões de beneficiários. De dezembro de 2014 a dezembro de 2015, houve uma queda de 2,2\% do número de usuários de planos médico-hospitalares, ou seja, o sistema de saúde suplementar passou de 50,4 milhões a 49,3 milhões de beneficiários, distribuídos em 824 operadoras de planos médico-hospitalares ativas no Brasil ${ }^{13}$.

O número de beneficiários de planos privados médico-hospitalares continuou a cair. Em dezembro de 2016, o mercado de assistência médico-hospitalar contava

11 Esses dados da Agência Nacional de Saúde Suplementar - ANS são referentes ao mês de janeiro de 2018. BRASIL. Agência Nacional de Saúde Suplementar. Sala de situação. Disponível em: <http://www.ans.gov.br/perfil-do-setor/dados-e-indicadores-do-setor/sala-de-situacao>. Acesso em: 07 mar. 2018.

12 BRASIL. Agência Nacional de Saúde Suplementar. Dados e indicadores do setor. Disponível em:

<http://www.ans.gov.br/images/stories/Materiais_para_pesquisa/Perfil_setor/Caderno_informacao _saude_suplementar/2015_mes06_caderno_informacao.pdf>. Acesso em: 27 mar. 2017.

13 BRASIL. Agência Nacional de Saúde Suplementar. Dados gerais. Disponível em: <http://www.ans.gov.br/perfil-do-setor/dados-gerais>. Acesso em: 09 maio 2017. 
CAMINHA, Uinie; NORÕES, Mariane. Mercado de saúde suplementar no Brasil e a seleção adversa: uma análise econômica a partir da política de controle de preços dos planos individuais. Revista Eletrônica Direito e Política, Programa de Pós-Graduação Stricto Sensu em Ciência Jurídica da UNIVALI, Itajaí, v.13, n.3, $3^{\circ}$ quadrimestre de 2018. Disponível em: www.univali.br/direitoepolitica - ISSN 1980-7791

com 47,9 milhões de beneficiários em 789 operadoras ativas no Brasil. Isso significou uma retração de $2,8 \%$ de beneficiários, em relação ao mês de dezembro do ano anterior. Ocorre que, essa evasão se deu nas faixas etárias de 0 a 18 anos $(-3,5 \%)$ e 19 a 58 anos $(-3,4 \%)$, ao passo que aumentou em $1,6 \%$ ao ano o vínculo de beneficiários de 59 anos ou mais a planos privados de assistência médico-hospitalar ${ }^{14}$.

Uma das razões para este cenário é a recessão econômica enfrentada pelo Brasil nos últimos anos, a qual gerou um efeito negativo no mercado de trabalho e, consequentemente, nas contratações de planos de saúde. Segundo Pesquisa Nacional por Amostragem de Domicílio - PNAD, do Instituto Brasileiro de Geografia e Estatística - IBGE, o Brasil encerrou o ano de 2015 com taxa de desocupação da população ativa em 9\%. Isso correspondia a 9,073 milhões de pessoas. No 40 trimestre de 2016, o índice de pessoas desocupadas passou de $9 \%$ a $12 \%$. Mais de 12,3 milhões de brasileiros estavam em situação de desemprego no final de 2016. Ainda continua a aumentar o número de pessoas desocupadas. No 10 trimestre de 2017, a taxa de desocupação foi estimada em $13,7 \%$, sendo 1,7 pontos percentuais a mais em comparação ao 40 trimestre de 2016. O total, estimado, da população ocupada é de 88,9 milhões de pessoas ${ }^{15}$.

Outro fator importante na retração do mercado de saúde suplementar foi apontado pelo Instituto de Estudos de Saúde Suplementar - IESS. Segundo o IESS $^{16}$, a influência do Governo no controle de preço dos planos individuais causa o aumento do custo de manutenção desses planos pelas operadoras,

14 BRASIL. Instituto de Estudos de Saúde Suplementar. Saúde Suplementar em Números. Disponível em: <http://documents.scribd.com.s3.amazonaws.com/docs/7pydrps16o5rf6n0.pdf>. Acesso em: 08 jun. 2017.

15 Para a realização da Pesquisa Nacional por Amostragem de Domicílio - PNAD, o Instituto Brasileiro de Geografia e Estatística - IBGE, considerou a população em idade ativa, que são todas as pessoas com 14 anos ou mais. BRASIL. Fundação Instituto Brasileiro de Geografia e Estatística. Pesquisa Nacional por Amostra de Domicílios Contínua Primeiro trimestre de 2017. Disponível em: <ftp://ftp.ibge.gov.br/Trabalho_e_Rendimento/Pesquisa_Nacional_por_Amostra_de_Domicilios_con tinua/Trimestral/Fasciculos_Indicadores_IBGE/pnadc_201701_trimestre_caderno.pdf $>$ Acesso em: 08 jun. 2017.

16 BRASIL. Instituto de Estudos de Saúde Suplementar. Determinantes da posse de plano de saúde. maio 2017. 
CAMINHA, Uinie; NORÕES, Mariane. Mercado de saúde suplementar no Brasil e a seleção adversa: uma análise econômica a partir da política de controle de preços dos planos individuais. Revista Eletrônica Direito e Política, Programa de Pós-Graduação Stricto Sensu em Ciência Jurídica da UNIVALI, Itajaí, v.13, n.3, $3^{\circ}$ quadrimestre de 2018. Disponível em: www.univali.br/direitoepolitica - ISSN 1980-7791

reverberando em um consequente encarecimento das mensalidades, o que, por sua vez, torna tal produto menos atrativo ao consumidor de menor risco.

Nesta sequência de causa e efeito, vislumbra-se o fenômeno da seleção adversa no mercado de saúde suplementar. Os indivíduos pertencentes aos grupos de riscos mais elevados serão levados a se utilizar dos planos de saúde, ao passo que aqueles pertencentes aos grupos de menor risco findarão por abandonar a saúde suplementar e optar pela saúde pública, o que provoca, além do desequilíbrio econômico-financeiro do próprio plano de saúde, uma pressão de demanda junto ao setor público de saúde.

Diante do problema exposto, o presente artigo objetiva analisar como a política de controle de preços dos planos de saúde na modalidade individual ou familiar gera seleção adversa no mercado de saúde suplementar. A princípio, o estudo fará uma abordagem geral do mercado de saúde suplementar. Posteriormente, tratar-se-á da regulação dos preços dos planos individuais. E, ao final, serão analisados dados oficiais de órgãos públicos e a seleção adversa no mercado de saúde suplementar, a partir da política de controle de preços dos planos individuais.

A metodologia, quanto à abordagem ou à natureza do estudo, é do tipo bibliográfico e documental, com pesquisa pura de abordagem qualitativa, uma vez que a investigação foi realizada com base em livros, legislação pátria, artigos científicos de periódicos nacionais, dissertações, teses e dados oficiais publicados na Internet. Quanto à finalidade da pesquisa, o presente trabalho apresenta cunho descritivo e exploratório, porque busca expor, explicar e descrever como a política de controle de preços dos planos individuais provoca seleção adversa no mercado de saúde suplementar.

\section{MERCADO DE SAÚDE SUPLEMENTAR NO BRASIL}

O mercado de saúde suplementar no Brasil surgiu entre as décadas de 1920 e 1930, quando foram instituídas as primeiras organizações previdenciárias e de assistência privada à saúde dos trabalhadores. De modo preciso, em 24 de janeiro de 1923, o Decreto no 4.682, ou mais conhecida, a Lei Eloy Chaves, criou 
CAMINHA, Uinie; NORÕES, Mariane. Mercado de saúde suplementar no Brasil e a seleção adversa: uma análise econômica a partir da política de controle de preços dos planos individuais. Revista Eletrônica Direito e Política, Programa de Pós-Graduação Stricto Sensu em Ciência Jurídica da UNIVALI, Itajaí, v.13, n.3, $3^{\circ}$ quadrimestre de 2018. Disponível em: www.univali.br/direitoepolitica - ISSN 1980-7791

as primeiras Caixas de Aposentadoria e Pensões, voltadas aos trabalhadores das estradas de ferro. As Caixas de Aposentadoria e Pensões eram fundos gerenciados e financiados por empregadores e empregados que, além de garantirem aposentadorias e pensões, também pagavam os serviços médicohospitalares aos trabalhadores e seus dependentes ${ }^{17}$.

Todavia, a efetiva difusão dos serviços privados à saúde acorreu apenas por volta de 1970, quando estes foram estendidos a qualquer pessoa que pudesse e quisesse pagá-los, seja de forma direta ao prestador do serviço, seja por meio da contratação de plano ou seguro de saúde ${ }^{18}$.

Antes do advento da Constituição Federal de 1988, o único regramento previsto no mercado de saúde suplementar era o Decreto-Lei no 73/66, que criou e disciplinou o seguro-saúde e os serviços de saúde pré-pagos. Nesse momento, não existia lei que tratasse sobre a formação e a organização das operadoras de planos de saúde, e muito menos sobre a sua fiscalização. O resultado disto foi o crescimento desordenado do setor de saúde suplementar e a eminente assimetria de informações entre a operadora e o consumidor, que levava à prática de condutas abusivas por parte das operadoras em face aos consumidores.

Somente após a Constituição Federal de 1988, com a edição do Código de Defesa do Consumidor, de 11 de setembro de 1990, seguido da publicação da Lei no 9.656 (Lei dos Planos de Saúde), de 03 de junho de 1998, e a criação da Agência Nacional de Saúde Suplementar - ANS, por meio da Lei no 9.961, em 28 de janeiro de 2000, o mercado de saúde suplementar passou a ser regulamentado e fiscalizado, aumentando, assim, a confiança dos consumidores neste tipo de atividade econômica. A título de exemplo, antes da Lei no 9.656/98 as

17 GOMES, Josiane Araújo. Contratos de Planos de Saúde: a busca judicial pelo equilíbrio de interesses entre os usuários e as operadoras de planos de saúde. Leme (SP): JH Mizuno, 2016.

18 GONÇALVES, Sandra Krieger. Judicialização do direito à saúde e o sistema de saúde suplementar no Brasil: aspectos críticos da fundamentação de decisões judiciais. Rio de Janeiro: Lumen Juris, 2016. 
CAMINHA, Uinie; NORÕES, Mariane. Mercado de saúde suplementar no Brasil e a seleção adversa: uma análise econômica a partir da política de controle de preços dos planos individuais. Revista Eletrônica Direito e Política, Programa de Pós-Graduação Stricto Sensu em Ciência Jurídica da UNIVALI, Itajaí, v.13, n.3, $3^{\circ}$ quadrimestre de 2018. Disponível em: www.univali.br/direitoepolitica - ISSN 1980-7791

operadoras contavam com 5.012.453 beneficiários, ao passo que, logo após a Lei no 9.656/98, elas tiveram um aumento de 42.886 .334 usuários $^{19}$.

O complexo mercado de saúde suplementar é essencialmente formado pelas operadoras de assistência privada à saúde, beneficiários, prestadores de serviço, profissionais da saúde, fornecedores de insumos e a $\mathrm{ANS}^{20}$, cuja atuação nesse mercado é disciplinada pelo Estado. Adiante, buscar-se-á analisar os agentes que compõem o mercado de saúde suplementar e a sua regulamentação, sem, contudo, aprofundar seus aspectos, pois fugiria ao tema.

A Lei Federal dos Planos de Saúde (Lei no 9.656/98), no artigo 10, caput, inciso II, define as operadoras de saúde como "pessoa jurídica constituída sob a modalidade de sociedade civil ou comercial, cooperativa, ou entidade de autogestão, que opere produto, serviço ou contrato de que trata o inciso I deste

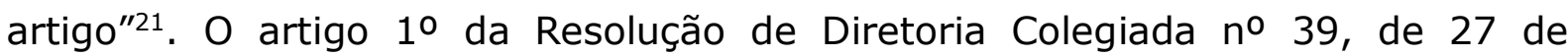
outubro de 2000, completa essa definição, ao estabelecer que a operadora de plano de assistência à saúde são empresas e entidades que operam planos de assistência à saúde no mercado de saúde suplementar, referindo à palavra "operar" as atividades de administração, comercialização e disponibilização de planos $^{22}$.

Deste modo, as operadoras de planos e seguros de saúde são empresas e entidades que exercem o papel de intermediária do usuário ao serviço de saúde, na medida em que é responsável pela captação, distribuição e utilização dos

\footnotetext{
19 BRASIL. Instituto de Estudos de Saúde Suplementar. Saúde Suplementar em Números. Online.

20 CUNHA JÚNIOR, Luiz Arnaldo Pereira da. O mercado de saúde suplementar - a busca do equilíbrio. IN: NOBRE, Milton Augusto de Brito; SILVA, Ricardo Augusto Dias da (org.). O CNJ e os desafios da efetivação do direito à saúde. Belo Horizonte: Fórum, 2011, p. 273-301.
}

${ }^{21}$ BRASIL. Lei no 9.656 de 03 de junho de 1998. Dispõe sobre os planos e seguros privados de assistência à saúde. In: Diário Oficial da República Federativa do Brasil, Brasília, DF, 03 jun. 1998. Disponível em: <http://www.planalto.gov.br/ccivil_03/leis/L9656.htm>. Acesso em: 27 nov. 2017.

22 BRASIL. Agência Nacional de Saúde Suplementar. Resolução de Diretoria Colegiada no 39 de 27 de outubro de 2000. Dispõe sobre a definição, a segmentação e a classificação das Operadoras de Planos de Assistência à Saúde. In: Diário Oficial da União, Brasília, DF, 30 out. 2000. Disponível em: <http://www.ans.gov.br/component/legislacao/?view=legislacao\&task=TextoLei\&format=raw\&id= Mzgw>. Acesso em: 28 nov. 2017. 
CAMINHA, Uinie; NORÕES, Mariane. Mercado de saúde suplementar no Brasil e a seleção adversa: uma análise econômica a partir da política de controle de preços dos planos individuais. Revista Eletrônica Direito e Política, Programa de Pós-Graduação Stricto Sensu em Ciência Jurídica da UNIVALI, Itajaí, v.13, n.3, $3^{\circ}$ quadrimestre de 2018. Disponível em: www.univali.br/direitoepolitica - ISSN 1980-7791

recursos de um fundo comum. Esse fundo decorre do regime financeiro seguido pelas operadoras, qual seja: o Regime Financeiro de Repartição Simples. Isto é, as mensalidades pagas pelos beneficiários irão para um fundo comum, o qual custeará as despesas de assistência médica, hospitalar e odontológica de todos os beneficiários e despesas não assistenciais da atividade econômica dos planos de saúde. A gestão desse fundo compete às operadoras de saúde ${ }^{23}$.

Segundo a Resolução de Diretoria Colegiada no 39/00 e a Lei no 10.185/01, as operadoras deverão ser constituídas na forma de: administradora de benefícios, cooperativa médica, cooperativa odontológica, autogestão, filantropia, medicina de grupo, odontologia de grupo ou seguradora especializada em saúde ${ }^{24}$. Dentre estas modalidades, a administradora de benefício é a única que não é espécie, propriamente dita, de operadoras de planos de saúde, e sim uma intermediária das contratações entre os consumidores e as operadoras, conforme se infere dos artigos $3^{\circ}$ e $8^{\circ}$ da Resolução Normativa no 196/09 da ANS ${ }^{25}$.

Já a cooperativa médica e a cooperativa odontológica são sociedades de pessoas que reciprocamente se obrigam a contribuir com bens ou serviços de saúde para o exercício de uma atividade econômica, de proveito comum, sem fins lucrativos, segundo previsão dos artigos $3^{\circ}$ e $4^{\circ}$, da Lei no 5.764/71 26 . Nesta modalidade de operadora, os médicos e odontologistas são, simultaneamente, sócios e

23 GOMES, Josiane Araújo. Contratos de Planos de Saúde: a busca judicial pelo equilíbrio de interesses entre os usuários e as operadoras de planos de saúde.

24 BRASIL. Lei no 10.185 de 12 de fevereiro de 2001. Dispõe sobre a especialização das sociedades seguradoras em planos privados de assistência à saúde e dá outras providências. In: Diário Oficial da República Federativa do Brasil, Brasília, DF, 14 fev. 2001. Disponível em: <http://www.planalto.gov.br/ccivil_03/leis/LEIS_2001/L10185.htm>. Acesso em: 07 fev. 2018.

25 Os artigos $3^{\circ}$ e $8^{\circ}$ da Resolução Normativa no 196/09 preveem, respectivamente, que "a Administradora de Benefícios não poderá atuar como representante, mandatária ou prestadora de serviço da Operadora de Plano de Assistência à Saúde nem executar quaisquer atividades típicas da operação de planos privados de assistência à saúde", bem como "não poderá ter rede própria, credenciada ou referenciada de serviços médico-hospitalares ou odontológicos, para oferecer aos beneficiários da pessoa jurídica contratante". BRASIL. Agência Nacional de Saúde Suplementar. Resolução Normativa no 196 de 14 de julho de 2009. Dispõe sobre a Administradora de Benefícios. In: Diário Oficial da União, Brasília, DF, 19 jul. 2009. Disponível em: <http://www.ans.gov.br/component/legislacao/?view=legislacao\&task=TextoLei\&format=raw\&id= $M T Q 10 Q==>$. Acesso em: 27 nov. 2017.

26 BRASIL. Lei no 5.764 de 16 de dezembro de 1971. Define a Política Nacional de Cooperativismo, institui o regime jurídico das sociedades cooperativas, e dá outras providências. In: Diário Oficial da República Federativa do Brasil, Brasília, DF, 16 dez. 1971. Disponível em: <http://www.planalto.gov.br/ccivil_03/leis/L5764.htm>. Acesso em: 28 nov. 2017. 
CAMINHA, Uinie; NORÕES, Mariane. Mercado de saúde suplementar no Brasil e a seleção adversa: uma análise econômica a partir da política de controle de preços dos planos individuais. Revista Eletrônica Direito e Política, Programa de Pós-Graduação Stricto Sensu em Ciência Jurídica da UNIVALI, Itajaí, v.13, n.3, $3^{\circ}$ quadrimestre de 2018. Disponível em: www.univali.br/direitoepolitica - ISSN 1980-7791

prestadores de serviços de saúde, "sendo remunerados pela produção individual, além de participar, ao final de cada exercício, do rateio do resultado obtido pela sociedade" 27 .

No que se refere às entidades de autogestão, a sua principal característica é o fato dos planos de saúde por elas geridos não estarem à disposição dos consumidores em geral, mas apenas a um grupo restrito, conforme se extrai da Resolução Normativa no 137/0628. Por exemplo, a Fundação Assistencial dos Servidores do Ministério da Fazenda - ASSEFAZ ${ }^{29}$ é uma entidade de autogestão prestadora de assistência médica, odontológica, farmacêutica e social aos servidores do Ministério da Fazenda e seus dependentes.

A filantropia é outra espécie de operadora de plano de saúde e tem a sua classificação no artigo 17 da Resolução de Diretoria Colegiada no 39/00, in verbis:

Classificam-se na modalidade de filantropia as entidades sem fins lucrativos que operam Planos Privados de Assistência à Saúde e tenham obtido o certificado de entidade beneficente de assistência social emitido pelo Ministério competente, dentro do prazo de validade, bem como da declaração de utilidade pública federal junto ao Ministério da Justiça ou declaração de utilidade pública estadual ou municipal junto aos Órgãos dos Governos Estaduais e Municipais, na forma da regulamentação normativa específica vigente ${ }^{30}$.

A medicina e a odontologia de grupo também foram classificadas pela Resolução de Diretoria Colegiada no 39/00, porém de forma residual. A medicina e a

27 SAMPAIO, Aurisvaldo. Contratos de Plano de Saúde: regime jurídico e proteção do sujeito mais fraco das relações de consumo. (Biblioteca de Direito do Consumidor, v. 40). São Paulo: Revista dos Tribunais, 2010, p. 219.

28 BRASIL. Agência Nacional de Saúde Suplementar. Resolução Normativa no 137 de 14 de novembro de 2006. Dispõe sobre as entidades de autogestão no âmbito do sistema de saúde suplementar. In: Diário Oficial da União, Brasília, DF, 20 nov. 2006. Disponível em: <http://www.ans.gov.br/component/legislacao/?view=legislacao\&task=TextoLei\&format=raw\&id= $M T E X N w==>$. Acesso em: 28 nov. 2017.

29 A Fundação Assistencial dos Servidores do Ministério da Fazenda - ASSEFAZ pode ser visualizada no sítio eletrônico: <http://www.assefaz.org.br/novo/assefaz/institucional>. Acesso em: 12 maio 2017.

30 BRASIL. Agência Nacional de Saúde Suplementar. Resolução de Diretoria Colegiada no 39 de 27 de outubro de 2000. Online. 
CAMINHA, Uinie; NORÕES, Mariane. Mercado de saúde suplementar no Brasil e a seleção adversa: uma análise econômica a partir da política de controle de preços dos planos individuais. Revista Eletrônica Direito e Política, Programa de Pós-Graduação Stricto Sensu em Ciência Jurídica da UNIVALI, Itajaí, v.13, n.3, $3^{\circ}$ quadrimestre de 2018. Disponível em: www.univali.br/direitoepolitica - ISSN 1980-7791

odontologia de grupo são empresas ou entidades que operam planos privados de assistência à saúde (artigo 15), ou planos exclusivamente odontológicos (artigo 16), excetuando-se aquelas constituídas como administradora de benefícios, cooperativa médica, cooperativa odontológica, autogestão ou filantropia ${ }^{31}$.

A partir da Lei no 10.185/01, a sociedade de seguro saúde foi considerada uma operadora de plano de assistência privada à saúde e o seu seguro saúde foi enquadrado como plano privado de assistência à saúde ${ }^{32}$. Assim, a seguradora de saúde passou a ser subordinada à disciplina do Conselho Nacional de Seguro Privado - CONSU e às normas e fiscalização da Agência Nacional de Saúde Suplementar - ANS.

Conforme a ANS, em janeiro de 2018, o mercado de saúde suplementar contava com 1.253 operadoras de planos e seguros de saúde com registro ativo no mercado de saúde suplementar, dentre as quais 1.054 apresentavam beneficiários cadastrados. Destas 1.054 operadoras de plano de assistência à saúde, 161 são autogestão, 293 são cooperativas médicas, 105 são cooperativas odontológicas, 44 são filantropias, 256 medicina de grupo, 186 são odontologia de grupo e 9 são seguradoras especializadas em saúde ${ }^{33}$.

Ao lado das operadoras de planos de saúde, há todo o conjunto dos profissionais da medicina e prestadores de serviços, como os hospitais, clínicas, consultórios, laboratórios e centros de diagnósticos. Para atender este conjunto de prestadores, existem os fornecedores de insumos, ou seja, a indústria de equipamentos, medicamentos e dispositivos médicos e sua rede distribuidora ${ }^{34}$.

Quanto aos beneficiários de planos de saúde, existem três tipos básicos de usuários: (1) os de planos coletivos empresariais; (2) os de planos coletivos por

31 BRASIL. Agência Nacional de Saúde Suplementar. Resolução de Diretoria Colegiada no 39 de 27 de outubro de 2000. Online.

32 BRASIL. Lei no 10.185 de 12 de fevereiro de 2001. Online.

33 BRASIL. Agência Nacional de Saúde Suplementar. Sala de situação. Online.

34 CECHIN, José. Saúde na idade - por que diferenciar preços de planos de saúde por idade e consequências econômicas da não aplicação dos reajustes previstos em contrato. IN: NOBRE, Milton Augusto de Brito; SILVA, Ricardo Augusto Dias da (org.). O CNJ e os desafios da efetivação do direito à saúde. Belo Horizonte: Fórum, 2011, p. 149-170. 
CAMINHA, Uinie; NORÕES, Mariane. Mercado de saúde suplementar no Brasil e a seleção adversa: uma análise econômica a partir da política de controle de preços dos planos individuais. Revista Eletrônica Direito e Política, Programa de Pós-Graduação Stricto Sensu em Ciência Jurídica da UNIVALI, Itajaí, v.13, n.3, $3^{\circ}$ quadrimestre de 2018. Disponível em: www.univali.br/direitoepolitica - ISSN 1980-7791

adesão; e (3) os de planos individuais ou familiares. Além disso, podem-se segmentar ainda mais os beneficiários em: os com planos "antigos" e os com planos "novos"35. Os beneficiários de planos antigos são aqueles que celebraram contrato privado de assistência à saúde até $1^{0}$ de janeiro de 1999 e não adaptaram à Lei no 9.656/98 36 . Neste caso, deverá ser aplicado aos beneficiários o disposto no contrato, e não o previsto nessa Lei. Já os beneficiários de planos novos são aqueles que contrataram o plano depois de $1^{0}$ de janeiro de 1999 e, por isso, estão subordinados ao sistema previsto na Lei dos Planos de Saúde ${ }^{37}$.

Segundo dados da ANS, o mercador de saúde suplementar tem mais de 70 milhões de beneficiários de planos privados de assistência médica com ou sem odontologia e planos privados exclusivamente odontológicos no Brasil. Do total de usuários, 48.724.693 são por contrato coletivo empresarial, 8.289.989 são por contrato coletivo por adesão e 13.257.027 são por contrato individual ou familiar ${ }^{38}$.

A ANS editou ainda a Resolução Normativa no 195, em 14 de julho de 2009, a fim de dispor sobre a classificação e as características desses planos privados de assistência à saúde. O plano coletivo empresarial é caracterizado como "aquele que oferece cobertura da atenção prestada à população delimitada e vinculada à pessoa jurídica por relação empregatícia ou estatutária" (artigo 50). O plano empresarial por adesão é aquele que oferece cobertura da atenção prestada à população que possua vínculo de caráter profissional, classista ou setorial com conselhos profissionais e entidades de classe, sindicatos, centrais sindicais e respectivas federações e confederações, associações profissionais legalmente

\footnotetext{
35 CUNHA JÚNIOR, Luiz Arnaldo Pereira da. O CNJ e os desafios da efetivação do direito à saúde, p. 273-301.

36 Artigo 35. Aplicam-se as disposições desta Lei a todos os contratos celebrados a partir de sua vigência, assegurada aos consumidores com contratos anteriores, bem como àqueles com contratos celebrados entre 2 de setembro de 1998 e 1 o de janeiro de 1999, a possibilidade de optar pela adaptação ao sistema previsto nesta Lei. BRASIL. Lei no 9.656 de 03 de junho de 1998. Online.
}

37 MATA, Beatriz Resende Rios da. Impacto Financeiro de 2010 a 2030 do envelhecimento dos beneficiários em operadoras de planos de saúde de Minas Gerais: um estudo de caso. 2011. 148f. Dissertação (Mestrado). Centro de Desenvolvimento e Planejamento Regional, Universidade Federal de Minas Gerais, Belo Horizonte. 2011.

${ }^{38}$ BRASIL. Agência Nacional de Saúde Suplementar. Sala de situação. Online. 
CAMINHA, Uinie; NORÕES, Mariane. Mercado de saúde suplementar no Brasil e a seleção adversa: uma análise econômica a partir da política de controle de preços dos planos individuais. Revista Eletrônica Direito e Política, Programa de Pós-Graduação Stricto Sensu em Ciência Jurídica da UNIVALI, Itajaí, v.13, n.3, $3^{\circ}$ quadrimestre de 2018. Disponível em: www.univali.br/direitoepolitica - ISSN 1980-7791

constituídas, cooperativas que congreguem membros de categorias ou classes de profissões regulamentadas, caixas de assistência e fundações de direito privado que se enquadrem nas disposições desta resolução e entidades representativas dos estudantes (artigo 90). Por último, o plano individual ou familiar é "aquele que oferece cobertura da atenção prestada para a livre adesão de beneficiários, pessoas naturais, com ou sem grupo familiar" (artigo $\left.3^{\circ}\right)^{39}$.

Quanto ao último agente que compõe o mercado de saúde suplementar, a ANS é uma autarquia de regime especial, vinculada ao Ministério da Saúde, com atuação em todo o território nacional, conforme previsto no artigo $1^{0}$ da Lei no 9.961/0040. Como órgão de regulação, a ANS estabelece ações normativas e fiscalizadoras, a fim de definir as regras de funcionamento de mercado de saúde suplementar e uniformizar a atividade econômica dos planos e seguros de saúde. Neste diapasão, Sandra Krieger Gonçalves conclui que o principal papel da ANS é harmonizar os interesses do Estado, das operadoras e dos consumidores, para que nenhum interesse seja privilegiado em detrimento do outro ${ }^{41}$.

Apresentado o mercado de saúde suplementar no Brasil, verifica-se que a regulamentação do setor privado de saúde e a criação da ANS, apesar de recentes, surgiram para diminuir as falhas de mercado, advindas, primordialmente, de um ambiente marcado pela assimetria de informações.

Entretanto, a regulação trouxe outras falhas de mercado. Segundo o Parecer Técnico da Fundação Instituto de Pesquisas Contábeis, Atuariais e Financeiras FIPECAFI, desenvolvido a pedido do Instituto de Estudos de Saúde Suplementar -

39 BRASIL. Agência Nacional de Saúde Suplementar. Resolução Normativa no 195 de 14 de julho de 2009. Dispõe sobre a classificação e características dos planos privados de assistência à saúde, regulamenta a sua contratação, institui a orientação para contratação de planos privados de assistência à saúde e dá outras providências. In: Diário Oficial da União, Brasília, DF, 15 jul. 2009.

Disponível

em: <http://www.ans.gov.br/component/legislacao/?view=legislacao\&task=TextoLei\&format=raw\&id= MTQ1OA==>. Acesso em: 07 mar. 2018.

40 BRASIL. Lei no 9.961 de 28 de janeiro de 2000. Cria a Agência Nacional de Saúde Suplementar - ANS e dá outras providências. In: Diário Oficial da República Federativa do Brasil, Brasília, DF, 28 jan. 2000. Disponível em: <http://www.planalto.gov.br/ccivil_03/leis/L9961.htm>. Acesso em: 27 nov. 2017.

41 GONÇALVES, Sandra Krieger. Judicialização do direito à saúde e o sistema de saúde suplementar no Brasil: aspectos críticos da fundamentação de decisões judiciais. 
CAMINHA, Uinie; NORÕES, Mariane. Mercado de saúde suplementar no Brasil e a seleção adversa: uma análise econômica a partir da política de controle de preços dos planos individuais. Revista Eletrônica Direito e Política, Programa de Pós-Graduação Stricto Sensu em Ciência Jurídica da UNIVALI, Itajaí, v.13, n.3, $3^{\circ}$ quadrimestre de 2018. Disponível em: www.univali.br/direitoepolitica - ISSN 1980-7791

IESS, a política de reajuste dos preços dos planos individuais ou familiares gerou o fenômeno da seleção adversa no setor de saúde suplementar, ou seja:

Indivíduos de baixo risco (jovens) tenderão a não contratar o plano ou a deixá-lo, enquanto indivíduos de alto risco (idosos) terão incentivos a contratá-lo. Isto altera o perfil de risco do grupo segurado, aumentando o custo do plano e, assim, afastando ainda mais os consumidores de menor risco da contratação. No extremo, esse mecanismo pode levar à extinção do mercado ${ }^{42}$.

Para a compreensão desse fenômeno denominado "seleção adversa" no mercado de saúde suplementar, decorrente da regulação estatal, será analisada, no tópico seguinte, a política de preços dos planos privados de assistência à saúde. A partir daí, buscar-se-á conhecer os limites impostos pela Administração Pública à autonomia das operadoras quanto ao reajuste das contraprestações pecuniárias dos planos individuais ou familiares.

\section{POLÍtICA DE CONTROLE DE PREÇOS DOS PLANOS INDIVIDUAIS DE ASSISTÊNCIA À SAÚDE}

Após anos de intensos debates pelo Poder Legislativo Federal para a elaboração de uma lei que disciplinasse os planos de assistência privada à saúde, em 03 de junho de 1998 - dez anos após a Constituição Federal de 1988 -, foi sancionada a Lei dos Planos de Saúde (Lei no 9.656), pelo Presidente da República, Fernando Henrique Cardoso. Este é o marco da regulamentação dos planos de saúde e, consequentemente, da regulação do reajuste de preços dos planos individuais.

Em 25 de novembro de 1999, com a edição da Medida Provisória no 1.928, reeditada pela Medida Provisória no 2012-2 e convertida na Lei no 9.961, de 28 de janeiro de 2000, foi criada a Agência Nacional de Saúde Suplementar (ANS), com competência para autorizar reajustes e revisões das contraprestações pecuniárias dos planos privados de assistência à saúde, ouvido o Ministério da Fazenda (artigo 40, XVII), expedir normas e padrões para o envio de informações

42 BRASIL. Fundação Instituto de Pesquisas Contábeis, Atuariais e Financeiras. Parecer Técnico: Diferenciação de Risco e Mensalidade ou Prêmio entre Faixas Etárias em Planos e Seguros de Saúde. São Paulo, ago./2009, p. $5 . \quad$ Disponível em: <http://www.fipecafi.org/downloads/newsletter/faixaetariaparecertecnicoatuarial.pdf>. Acesso em: 23 nov. 2017. 
CAMINHA, Uinie; NORÕES, Mariane. Mercado de saúde suplementar no Brasil e a seleção adversa: uma análise econômica a partir da política de controle de preços dos planos individuais. Revista Eletrônica Direito e Política, Programa de Pós-Graduação Stricto Sensu em Ciência Jurídica da UNIVALI, Itajaí, v.13, n.3, $3^{\circ}$ quadrimestre de 2018. Disponível em: www.univali.br/direitoepolitica - ISSN 1980-7791

de natureza econômico-financeira pelas operadoras, com vistas à homologação de reajustes e revisões (artigo 40, XVIII), monitorar a evolução dos preços de planos de assistência à saúde, seus prestadores de serviços, e respectivos componentes e insumos (artigo 40, XXI), fiscalizar a atuação das operadoras e prestadores de serviços de saúde e o cumprimento da Lei no 9.656/98 (artigo 40, XXVI e XXIX) ${ }^{43}$.

Com efeito, as operadoras de planos de saúde estão subordinadas à legislação pátria e à fiscalização da ANS. A questão é: Quais são os limites impostos pelo Estado à precificação dos planos de saúde? Antes de responder a esta pergunta, destaque-se que as operadoras são livres para estabelecer os preços dos planos de saúde, desde que obedeçam aos critérios previstos no ordenamento jurídico pátrio $^{44}$.

O primeiro limite se depreende da leitura do artigo 15 da Lei no 9.656/98, o qual admitiu a idade como a única condição para diferenciar o preço das mensalidades dos planos entre os consumidores. Para efeitos práticos desta norma, o Conselho de Saúde Suplementar - CONSU editou a Resolução no 6/98, fixando sete faixas etárias para a cobrança diferenciada das mensalidades, quais sejam: (1) 0 a 17 anos; (2) 18 a 29 anos; (3) 30 a 39 anos; (4) 40 a 49 anos; (5) 50 a 59 anos; (6) 60 a 69 anos; e (7) 70 anos ou mais. Além disso, o seu artigo 20 previa que as operadoras podiam adotar por critérios próprios os valores e fatores de acréscimos das contraprestações entre as faixas etárias, desde que o valor firmado para a última faixa etária não seja superior a seis vezes o valor da primeira faixa etária.

Entretanto, o artigo 15, $3^{\circ}$, da Lei no 10.741/03 (Estatuto do Idoso) vedou a discriminação do idoso - pessoa de 60 anos ou mais - nos contratos planos de

\footnotetext{
${ }^{43}$ Existem outras competências da ANS no artigo $4^{\circ}$ da Lei $9.961 / 00$, porém, em razão do estudo se restringir à política de reajuste de preços dos planos de saúde, foram descritas apenas essas competências. BRASIL. Lei no 9.961 de 28 de janeiro de 2000. Online.

44 CECHIN, José. Saúde na idade - por que diferenciar preços de planos de saúde por idade e consequências econômicas da não aplicação dos reajustes previstos em contrato. IN: NOBRE, Milton Augusto de Brito; SILVA, Ricardo Augusto Dias da (org.). O CNJ e os desafios da efetivação do direito à saúde, p. 149-170.
} 
CAMINHA, Uinie; NORÕES, Mariane. Mercado de saúde suplementar no Brasil e a seleção adversa: uma análise econômica a partir da política de controle de preços dos planos individuais. Revista Eletrônica Direito e Política, Programa de Pós-Graduação Stricto Sensu em Ciência Jurídica da UNIVALI, Itajaí, v.13, n.3, $3^{\circ}$ quadrimestre de 2018. Disponível em: www.univali.br/direitoepolitica - ISSN 1980-7791

saúde pela cobrança de valores diferenciados em razão da idade ${ }^{45}$. Assim, a ANS, com a finalidade de atender ao Estatuto do Idoso, editou a Resolução Normativa no 63/03, criando novos critérios para a variação de preço por faixa etária nos planos de saúde contratados a partir de $1^{\circ}$ de janeiro de 2004.

A Resolução Normativa n 63/03 estabeleceu dez faixas etárias, em substituição às sete faixas anteriores, quais sejam: (1) 0 a 18 anos; (2) 19 a 23 anos; (3) 24 a 28 anos; (4) 29 a 33 anos; (5) 34 a 38 anos; (6) 39 a 43 anos; (7) 44 a 48 anos; (8) 49 a 53 anos; (9) 54 a 58 anos; e (10) 59 anos ou mais (artigo 20). Além disso, determinou que a variação acumulada entre a sétima e décima faixas etárias não poderia ser maior do que a variação acumulada entre a primeira e a sétima, cujas variações apresentariam percentuais positivos (artigo 30, incisos II e III). Com relação ao valor da última faixa etária, este continuava não podendo ser superior a seis vezes o valor da primeira (artigo $\left.3^{\circ}\right)^{46}$.

Sobre o tema, importante registrar que está em votação na Câmara dos Deputados o Projeto de Lei no 7.419/06, do Senado Federal, que altera a Lei no 9.656/98. Dentre as propostas do projeto de lei estava a mudança no reajuste aplicado à última faixa etária, para contratos firmados após janeiro de 2004. A Comissão Especial da Câmara apresentou, no dia 18 de outubro de 2017, parecer favorável para permitir que o último reajuste fosse dividido em cinco parcelas, aplicado a cada cinco anos, com correção pelo Índice de Preços ao Consumidor IPCA $^{47}$. Ao invés de impor ao consumidor o pagamento de um reajuste de $100 \%$

45 BRASIL. Lei no 10.741 de $1^{0}$ de outubro de 2003. Dispõe sobre o Estatuto do Idoso e dá outras providências. In: Diário Oficial da República Federativa do Brasil, Brasília, DF, 12 fev. 2001. Disponível em: <http://www.planalto.gov.br/ccivil_03/leis/2003/L10.741.htm>. Acesso em: 28 nov. 2017.

46 BRASIL. Agência Nacional de Saúde Suplementar. Resolução Normativa no 63 de 22 de dezembro de 2003. Define os limites a serem observados para adoção de variação de preço por faixa etária nos planos privados de assistência à saúde contratados a partir de $1^{0}$ de janeiro de 2004. In: Diário Oficial da União, Brasília, DF, 23 dez. 2003. Disponível em: <http://www.ans.gov.br/component/legislacao/?view=legislacao\&task=TextoLei\&format=raw\&id=N zQ4>. Acesso em: 28 nov. 2017.

47 BRASIL. Câmara dos Deputados. Comissão Especial destinada a proferir parecer ao projeto de Lei no 7.419, de 2006, do Senado Federal, que "altera a Lei no 9.656, de 3 de junho de 1998, que dispõe sobre os planos e seguros privados de assistência à saúde", e apensados. Disponível em: <http://www2.camara.leg.br/atividadelegislativa/comissoes/comissoes-temporarias/especiais/55a-legislatura/pl-7419-06-planos-desaude/documentos/outros-documentos/parecer-do-relator-08-11-2017>. Acesso em: 07 dez. 2017. 
CAMINHA, Uinie; NORÕES, Mariane. Mercado de saúde suplementar no Brasil e a seleção adversa: uma análise econômica a partir da política de controle de preços dos planos individuais. Revista Eletrônica Direito e Política, Programa de Pós-Graduação Stricto Sensu em Ciência Jurídica da UNIVALI, Itajaí, v.13, n.3, $3^{\circ}$ quadrimestre de 2018. Disponível em: www.univali.br/direitoepolitica - ISSN 1980-7791

em uma única parcela, acrescer-se-ão à mensalidade da pessoa que atinge 59 anos $20 \%$ do total nominal, vencidas a cada cinco anos. Assim, o último reajuste na mensalidade seria diluído no período de 20 anos, encerrando quando o idoso completasse 79 anos de idade ${ }^{48}$.

Segundo o relator dessa proposta, o deputado federal Rogério Marinho (PSDBRN), essa alteração na política de preços dos planos de saúde seria uma vantagem aos consumidores, porque, de acordo com as regras atuais, há um grande reajuste a partir dos $59 \operatorname{anos}^{49}$. Todavia, as operadoras de planos de saúde alegaram prejuízo de aproximadamente $\mathrm{R} \$ 65$ bilhões nas suas receitas ao longo dos próximos 20 anos, o que geraria um desequilíbrio econômicofinanceiro. Em razão dessa reclamação, o relator do referido projeto de lei, em 29 de novembro de 2017, afastou de seu parecer essa regra que previa o parcelamento do reajuste de mensalidades dos beneficiários da última faixa etária em cinco vezes e a cada cinco anos, fixando prazo até 12 de dezembro de 2017 para receber novas sugestões de alteração do relatório do Projeto de Lei no 7419/0650. Em 9 de janeiro de 2018, a Câmara dos Deputados noticiou que analisou as propostas sobre o tema, porém o parecer do relator ainda não foi votado $^{51}$. Deste modo, verifica-se o interesse do Estado em colaborar com a manutenção do setor privado de saúde, porém falta-lhe ousadia para inovar e

48 BRASIL. Câmara dos Deputados. Confira as propostas para mudanças nas regras dos planos de saúde. Disponível em: <http://www2.camara.leg.br/camaranoticias/noticias/SAUDE/547584-CONFIRA-AS-PROPOSTASPARA-MUDANCA-NAS-REGRAS-DOS-PLANOS-DE-SAUDE.html>. Acesso em: 26 nov. 2017.

49 BRASIL. Câmara dos Deputados. Comissão Especial destinada a proferir parecer ao projeto de Lei no 7.419, de 2006, do Senado Federal, que "altera a Lei no 9.656, de 3 de junho de 1998, que dispõe sobre os planos e seguros privados de assistência à saúde", e apensados. Online.

50 BRASIL, Câmara dos Deputados. Planos de saúde: mudança no texto adia votação do relatório. Disponível em: <http://www2.camara.leg.br/camaranoticias/noticias/SAUDE/549945PLANOS-DE-SAUDE-MUDANCA-NO-TEXTO-ADIA-VOTACAO-DO-RELATORIO.html >. Acesso em: 08 dez. 2017.

51 BRASIL. Câmara dos Deputados. Propostas que alteram regras sobre planos de saúde voltarão a debate em 2018 . http://www2.camara.leg.br/camaranoticias/noticias/SAUDE/551600-PROPOSTAS-QUE-ALTERAMREGRAS-SOBRE-PLANOS-DE-SAUDE-VOLTARAO-A-DEBATE-EM-2018.html>. Acesso em: 07 mar. 2018. 
CAMINHA, Uinie; NORÕES, Mariane. Mercado de saúde suplementar no Brasil e a seleção adversa: uma análise econômica a partir da política de controle de preços dos planos individuais. Revista Eletrônica Direito e Política, Programa de Pós-Graduação Stricto Sensu em Ciência Jurídica da UNIVALI, Itajaí, v.13, n.3, $3^{\circ}$ quadrimestre de 2018. Disponível em: www.univali.br/direitoepolitica - ISSN 1980-7791

acrescentar novos critérios de reajuste de preços que aumentam a autonomia das partes contratantes, como a criação de critérios baseados no risco ${ }^{52}$.

No que se refere à política atual de controle de preços dos planos de saúde, a legislação em vigor deu origem a três modelos aplicáveis aos planos de saúde. 0 primeiro modelo diz respeito aos planos "antigos" não adaptados à Lei no 9.656/98. Neste caso, a variação de preço por faixa etária é regulada pelo próprio contrato. O segundo modelo refere-se aos contratos "antigos" adaptados à Lei n. 9.656/98 e aos celebrados entre 02 de janeiro de 1999 e 31 de dezembro de 2003. Aqui, os reajustes por faixa etária se darão nas sete faixas previstas da Resolução no 6/98. Por último, o terceiro modelo corresponde aos planos assinados a partir de 10 de janeiro de 2004 e aos contratos anteriores a essa data que foram adaptados à Resolução Normativa no 63/03. O terceiro modelo é o único modelo que é disciplinado pela Resolução Normativa n 63/03.

Com efeito, a política de controle de preços dos planos de saúde autorizou que as operadoras de planos de saúde diferenciassem as mensalidades de seus planos por faixa etária. Por outro lado, buscou proteger o beneficiário idoso, para que a mensalidade da última faixa etária não fosse excessivamente onerosa, a ponto de excluí-lo do mercado de saúde suplementar. Ocorre que os custos de tratamento das pessoas idosas tendem a ser mais elevados do que os custos de tratamento das pessoas mais jovens. Diante deste fato, questiona-se: Qual medida foi tomada pelo Estado para o equilíbrio econômico-financeiro do setor de saúde suplementar?

A ANS, por meio da Resolução Normativa no 191/0953, instituiu o Fundo Garantidor do Segmento de Saúde Suplementar - FGS, cuja gestão é das operadoras de planos de saúde ${ }^{54}$. Por conseguinte, todas as mensalidades pagas

52 BARROS, Pedro Pita. Economia da Saúde: conceitos contemporâneos.

53 A Resolução Normativa no 430, de 7 de dezembro de 2017, revogou a Resolução Normativa no 191, de 08 de maio de 2009.

54 BRASIL. Agência Nacional de Saúde Suplementar. Resolução Normativa no 191 de 08 de maio de 2009. Institui o Fundo Garantidor do Segmento de Saúde Suplementar (FGS) pelas Operadoras de Planos de Saúde. In: Diário Oficial da União, Brasília, DF, 13 maio 2009. Disponível em: <http://www.ans.gov.br/component/legislacao/?view=legislacao\&task=TextoLei\&format=raw\&id= $M T Q Y N Q==>$. Acesso em: 17 nov. 2017. 
CAMINHA, Uinie; NORÕES, Mariane. Mercado de saúde suplementar no Brasil e a seleção adversa: uma análise econômica a partir da política de controle de preços dos planos individuais. Revista Eletrônica Direito e Política, Programa de Pós-Graduação Stricto Sensu em Ciência Jurídica da UNIVALI, Itajaí, v.13, n.3, $3^{\circ}$ quadrimestre de 2018. Disponível em: www.univali.br/direitoepolitica - ISSN 1980-7791

pelos beneficiários irão para esse fundo comum, a fim de custear as despesas assistenciais e não assistenciais da atividade econômica dos planos de saúde com seus usuários, como visto no tópico anterior.

Além disso, a ANS adotou o Pacto Intergeracional, conforme documento da ANS intitulado "Análise de Nota Técnica Atuarial de Produtos (NTRP) e Pacto Intergeracional", o qual dispõe que:

O sistema de divisão de riscos na saúde suplementar brasileira é chamado de mutualismo com solidariedade intergeracional. Por "mutualismo" entende-se que, dentro de cada faixa etária, o prêmio é igual para todos os membros daquele plano e é determinado pelo risco médio daquele grupo. Ou seja, os indivíduos mais saudáveis (de menor risco) subsidiam aqueles menos saudáveis (de maior risco), dentro da mesma faixa etária. Em relação a solidariedade intergeracional, entende-se que os beneficiários das faixas etárias mais jovens (de menor risco) subsidiam os indivíduos mais idosos (de maior risco) ${ }^{55}$.

Assim, os beneficiários mais jovens, de menor custo, pagam um valor superior ao seu perfil de utilização, para subsidiarem parte dos custos dos beneficiários idosos. Igualmente, dentro da mesma faixa etária, os usuários mais saudáveis pagam valor além do que virão a utilizar, a fim de custear parte dos serviços de saúde daqueles usuários menos saudáveis. Essa é a forma de sustentação dos planos de saúde.

Além do reajuste de preço dos planos privados por mudança de faixa etária, as suas contraprestações pecuniárias são reajustadas anualmente, na data de aniversário do contrato, em razão, simultaneamente, do lucro esperado pelas operadoras, da variação de preços dos produtos no mercado e das despesas assistenciais, administrativas e comerciais, decorrentes da atividade econômica dos planos de saúde.

55 BRASIL. Agência Nacional de Saúde Suplementar. Análise de Nota Técnica Atuarial de Produtos (NTRP) e Pacto Intergeracional, 2011, p. 9. Disponível em: <http://www.ans.gov.br/images/stories/Legislacao/camara_tecnica/analise_ntrp.pdf>. Acesso em: 23 nov. 2017. 
CAMINHA, Uinie; NORÕES, Mariane. Mercado de saúde suplementar no Brasil e a seleção adversa: uma análise econômica a partir da política de controle de preços dos planos individuais. Revista Eletrônica Direito e Política, Programa de Pós-Graduação Stricto Sensu em Ciência Jurídica da UNIVALI, Itajaí, v.13, n.3, $3^{\circ}$ quadrimestre de 2018. Disponível em: www.univali.br/direitoepolitica - ISSN 1980-7791

Com a finalidade de monitorar o reajuste anual do preço dos planos de assistência privada à saúde, a ANS criou a Nota Técnica de Registro de Produto NTRP, através da Resolução de Diretoria Colegiada no 28/00, alterada pela Resolução da Diretoria Colegiada n 46/00 e pelas Resoluções Normativas nº 183/08, no 252/11 e no 304/1256. As Instruções Normativas da DIPRO no 08/02, n०19/08 e n० 23/09 complementam a regulamentação da NTRP.

Segundo os artigos $2^{\circ}$ e $3^{\circ}$ da Resolução de Diretoria Colegiada no 28/00, a NTRP é elaborada por atuário registrado no Instituto Brasileiro de Atuária - IBA, a partir de informações fornecidas pelas próprias operadoras de planos de saúde. A NTRP calcula o custo médio per capita para cada faixa etária e para cada item de despesa assistencial, levando-se em conta a frequência de utilização observada no ano anterior e o valor médio de cada um desses itens. Soma-se ao custo assistencial por faixa etária, a expectativa de despesas administrativas e comerciais. E, finalmente, a todas essas despesas é acrescido o lucro esperado pelas operadoras. Desta feita, a NTRP passou a definir os preços a serem adotados pelas operadoras nos próximos doze meses de comercialização, devendo a sua atualização ocorrer a cada doze meses ${ }^{57}$.

Em 29 de abril de 2008, a ANS editou a Resolução Normativa no 171/08, estabelecendo novos critérios para a aplicação do reajuste anual às contraprestações pecuniárias dos planos privados de assistência suplementar à saúde, com tratamento diferenciado para o plano individual (ou familiar) e o plano coletivo. O reajuste anual das mensalidades dos planos individuais depende de prévia autorização da ANS e não pode ultrapassar o reajuste máximo, ainda que seja comprovada, tecnicamente, a necessidade de um

\footnotetext{
56 Resolução de Diretoria Colegiada no 28/00: Artigo $1^{0}$ Parágrafo único. Esta Resolução aplica-se aos planos individuais e/ou familiares e aos planos coletivos, com exceção dos planos exclusivamente odontológicos e dos planos com formação de preço pós-estabelecido. BRASIL. Agência Nacional de Saúde Suplementar. Resolução de Diretoria Colegiada no 28 de 28 de junho de 2000. Altera a RDC no 4, de 18 de fevereiro de 2000, e institui a Nota Técnica de Registro de Produto. In: Diário Oficial da União, Brasília, DF, 28 jun. 2000. Disponível em: <http://www.ans.gov.br/component/legislacao/?view=legislacao\&task=TextoLei\&format=raw\&id= Mzg3>. Acesso em: 28 nov. 2017.

57 CECHIN, José. Saúde na idade - por que diferenciar preços de planos de saúde por idade e consequências econômicas da não aplicação dos reajustes previstos em contrato. IN: NOBRE, Milton Augusto de Brito; SILVA, Ricardo Augusto Dias da (org.). O CNJ e os desafios da efetivação do direito à saúde, p. 149-170.
} 
CAMINHA, Uinie; NORÕES, Mariane. Mercado de saúde suplementar no Brasil e a seleção adversa: uma análise econômica a partir da política de controle de preços dos planos individuais. Revista Eletrônica Direito e Política, Programa de Pós-Graduação Stricto Sensu em Ciência Jurídica da UNIVALI, Itajaí, v.13, n.3, $3^{\circ}$ quadrimestre de 2018. Disponível em: www.univali.br/direitoepolitica - ISSN 1980-7791

reajuste maior (artigo $2^{\circ}$ ). Ao passo que, o reajuste anual das mensalidades dos planos coletivos é livremente negociado pelas operadoras, bastando informar à ANS (artigo 13) ${ }^{58}$. Verifica-se, assim, uma maior interferência do Estado nos planos individuais, em comparação com os planos coletivos.

Apresentados os critérios de reajuste de preço dos planos de saúde individuais reajuste por mudança de faixa etária e reajuste anual -, passa-se no tópico seguinte a explicar como essa política de controle de preços gera seleção adversa no mercado de saúde suplementar.

\section{ANÁlise eCONÔMICA dA POLÍtica de CONTROLE de PREÇOS dOS PLANOS INDIVIdUAIS E A SELEÇÃo ADVERSA No MERCADO DE SAÚdE SUPLEMENTAR}

Como visto, a Lei Federal no 9.656/98, o Estatuto do idoso e a ANS exercem forte regulação sobre os preços dos planos de saúde, permitindo às operadoras de planos de saúde apenas modificarem os preços contratados por faixa de idade. Com base nisto, busca-se neste tópico verificar as eventuais consequências econômicas advindas da política de preços dos contratos de assistência privada à saúde na modalidade individual ou familiar. Para tanto, utilizou-se três documentos oficiais publicados na Internet, quais sejam: (1) a $5^{a}$ edição do Painel de Precificação, publicado pela ANS em 2017; (2) a edição de maio de 2017 do IESS sobre variação de custos médico-hospitalares; e (3) a projeção da população do Brasil por sexo e idade para o período de 2000 a 2060, publicado pelo IBGE, em 2013.

Na $5^{a}$ edição do Painel de Precificação ${ }^{59}$, constam os custos médios dos itens de despesas assistenciais, não assistenciais e margem de lucro de cada faixa etária

\footnotetext{
58 BRASIL. Agência Nacional de Saúde Suplementar. Resolução Normativa no 171 de 29 de abril de 2008. Estabelece critérios para aplicação de reajuste das contraprestações pecuniárias dos planos privados de assistência suplementar à saúde, médico-hospitalares, com ou sem cobertura odontológica, contratados por pessoas físicas ou jurídicas. In: Diário Oficial da União, Brasília, DF, $30 \quad$ abr. $2008 . \quad$ Disponível em: <http://www.ans.gov.br/component/legislacao/?view=legislacao\&task=TextoLei\&format=raw\&id= MTI4NA $==>$. Acesso em: 17 nov. 2017.

59 A 5 a edição do "Painel de Precificação: plano de saúde 2016" é um documento elaborado pela ANS, com informações fornecidas pelas próprias operadoras de planos de saúde, por intermédio de
} 
CAMINHA, Uinie; NORÕES, Mariane. Mercado de saúde suplementar no Brasil e a seleção adversa: uma análise econômica a partir da política de controle de preços dos planos individuais. Revista Eletrônica Direito e Política, Programa de Pós-Graduação Stricto Sensu em Ciência Jurídica da UNIVALI, Itajaí, v.13, n.3, $3^{\circ}$ quadrimestre de 2018. Disponível em: www.univali.br/direitoepolitica - ISSN 1980-7791

dos planos ambulatorial e hospitalar, de contratação individual ou familiar, do ano de $2016^{60}$. A escolha do documento ocorreu no intuito de se observar quanto a última faixa etária (59 anos ou mais) gasta em relação à primeira faixa etária (0 a 18 anos), para comparar com os limites legais.

A tabela seguinte traz a relação percentual e fatorial do custo médio por exposto $^{61}$ entre a última e a primeira faixa etária por item de despesa assistencial, calculada, respectivamente com base na variação percentual "P2/P1-1x100" e no fator "P/100+1":

Tabela 1 - Relação percentual e fatorial entre a última e a primeira faixa etária, por item de despesa, dos Planos Individuais com cobertura "Ambulatorial + Hospitalar".

\begin{tabular}{|l|l|l|l|l|}
\hline \multicolumn{1}{|c|}{$\begin{array}{c}\text { Itens de despesa } \\
\text { assistencial }\end{array}$} & $\begin{array}{c}\text { Custo por } \\
\text { exposto - 0 a } \\
\mathbf{1 8} \text { anos }\end{array}$ & $\begin{array}{c}\text { Custo por } \\
\text { exposto - 59 } \\
\text { anos ou mais }\end{array}$ & Percentual & Fator \\
\hline Consulta médica & $\mathrm{R} \$ 28,41$ & $\mathrm{R} \$ 44,55$ & $56,79 \%$ & 1,56 \\
\hline Exames complementares & $\mathrm{R} \$ 10,99$ & $\mathrm{R} \$ 64,23$ & $484,27 \%$ & 5,84 \\
\hline Terapias & $\mathrm{R} \$ 2,22$ & $\mathrm{R} \$ 19,90$ & $798,17 \%$ & 8,98 \\
\hline Internações atendimentos & $\mathrm{R} \$ 3,72$ & $\mathrm{R} \$ 206,93$ & $557,88 \%$ & 6,57 \\
\hline $\begin{array}{l}\text { Outros despesas } \\
\text { ambulatoriais }\end{array}$ & $\mathrm{R} \$ 5,89$ & $\mathrm{R} \$ 19,45$ & $423,37 \%$ & 5,23 \\
\hline $\begin{array}{l}\text { Demais } \\
\text { assistenciais }\end{array}$ & $\mathrm{R} \$ 37,75$ & $541,22 \%$ & 6,41 \\
\hline
\end{tabular}

Fonte: Painel de precificação - plano de saúde 2016 (extraído da base de NTRP, RPS e CADOP, em 07/06/2017).

dados e indicadores econômico-financeiros e estatísticos que constam nas Notas Técnicas de Registro de Produtos - NTRP do ano de 2016, elaboradas por atuário especializado.

60 BRASIL. Agência Nacional de Saúde Suplementar. Painel de Precificação: plano de saúde 2016. Rio de Janeiro, 2017.2 Disponível em: <http://www.ans.gov.br/images/stories/Materiais_para_pesquisa/Perfil_setor/Foco/painel_precifica cao2016.pdf>. Acesso em: 23 nov. 2017.

610 exposto corresponde aos beneficiários da operadora que estão fora do período de carência, ou seja, os beneficiários cujo risco está efetivamente coberto pelo plano. O custo por exposto é o custo desse beneficiário por mês. 
CAMINHA, Uinie; NORÕES, Mariane. Mercado de saúde suplementar no Brasil e a seleção adversa: uma análise econômica a partir da política de controle de preços dos planos individuais. Revista Eletrônica Direito e Política, Programa de Pós-Graduação Stricto Sensu em Ciência Jurídica da UNIVALI, Itajaí, v.13, n.3, $3^{\circ}$ quadrimestre de 2018. Disponível em: www.univali.br/direitoepolitica - ISSN 1980-7791

Depreende-se da leitura do quadro que, em relação à despesa com consulta médica, o custo por exposto da última faixa é 1,5 vezes maior do que a primeira faixa etária. Já, em exames complementares, o custo por exposto na faixa etária de 59 anos ou mais é 5,8 vezes mais oneroso do que a primeira. $E$, assim por diante, a variabilidade entre a última e a primeira faixa etária: em terapias, é de 8,9 vezes; em internações, é de 6,5 vezes; em outros atendimentos, é de 5,2 vezes; e, em demais despesas, é de 6,4 vezes.

Quanto ao total das despesas assistências, o custo por exposto da última faixa etária é $R \$ 392,81$ e o da primeira faixa etária é $R \$ 82,68$. Assim, a última faixa etária é $375,09 \%$ ou 4,7 vezes mais cara do que a primeira faixa etária ${ }^{62}$.

Soma-se às despesas assistenciais, as despesas não assistências e a margem de lucro das operadoras, que o documento denominou de "carregamentos". Segundo o referido documento, a variabilidade no carregamento total é pequena, menor que cinco pontos percentuais, no comparativo entre todas as faixas etárias. Nos demais itens, a diferença é inferior a dois pontos percentuais: 1,50 (lucro), 1,32 (administrativo) e 0,61 (comercial), evidenciando que a faixa etária não é um diferencial para se definir o percentual de carregamento.

Ao final, o valor da última faixa etária foi fixado em 5,7 vezes o valor da primeira faixa no ano de 2016. O limite máximo de 6 vezes estabelecido pela Resolução Normativa da ANS no 63/03 foi obedecido. Porém, esse valor está acima da diferença de despesas assistenciais e não assistenciais e margem de lucro. Ocorre que as operadoras de plano de saúde, assim como as seguradoras especializadas em saúde, levam em consideração a probabilidade de perdas, em vista de externalidade negativas aos contratos de planos de saúde, que aumentam seu custo de transação ${ }^{63}$.

A regulação de preços dos planos de saúde individuais pelo Poder Legislativo Federal e pela Agência Nacional de Saúde Suplementar pode ser considerada

62 O percentual e o fator são de elaboração própria. Utilizou-se a variação percentual "P2/P1$1 \times 100$ " e o fator "P/100+1". Assim, R\$ 392,81/R\$ 82,68-1x100 é igual a 375,09\% e 375,09/100+1 é igual ao fator 4,75 .

63 COASE, Ronald Harry. A firma, o mercado e o direito. Tradução de Heloisa Gonçalves Barbosa. Rio de Janeiro: Forense Universitária, 2016. 
CAMINHA, Uinie; NORÕES, Mariane. Mercado de saúde suplementar no Brasil e a seleção adversa: uma análise econômica a partir da política de controle de preços dos planos individuais. Revista Eletrônica Direito e Política, Programa de Pós-Graduação Stricto Sensu em Ciência Jurídica da UNIVALI, Itajaí, v.13, n.3, $3^{\circ}$ quadrimestre de 2018. Disponível em: www.univali.br/direitoepolitica - ISSN 1980-7791

uma externalidade. Entende-se por externalidade as decisões de agentes alheios ao contrato que afetam de forma positiva ou negativa as partes contratantes. Assim, quando o Poder Legislativo ou a agência reguladora cria ou modifica uma norma, os efeitos dessa medida irão ser sentidos pelos regulados. No caso das operadoras e dos beneficiários de planos de saúde, essa externalidades é negativa no momento em que gera maior custo na operação dos planos e seguros de saúde, porque esse custo será repassado às mensalidades, ainda que haja um controle do Estado64.

É certo que o preço de um produto afeta a quantidade de sua demanda. Esta, por sua vez, é "um resumo das escolhas ótimas que seriam realizadas pelo indivíduo dada a sua restrição orçamentária e suas preferências" ${ }^{\prime 65}$. Então, no que se refere à quantidade de demanda dos planos individuais, a edição de maio de 2017 do IESS ${ }^{66}$ apresenta o percentual total de beneficiários de planos individuais distribuídos por faixa etária no mês de setembro de 2016.

Tabela 2 - Distribuição dos beneficiários de planos individuais da ANS por faixa etária, em setembro de 2016.

\begin{tabular}{|c|c|}
\hline Faixa etária (anos) & Proporção de beneficiários (\%) \\
\hline $0-18$ & 28,3 \\
\hline $19-23$ & 5,3 \\
\hline $24-28$ & 6,1 \\
\hline $29-33$ & 6,6 \\
\hline $34-38$ & 6,8 \\
\hline $39-43$ & 5,7 \\
\hline $44-48$ & 5,2 \\
\hline $49-53$ & 5,5 \\
\hline $54-58$ & 5,6 \\
\hline 59 ou mais & 24,9 \\
\hline Total & 100 \\
\hline
\end{tabular}

Fonte: Variação de custos médico-hospitalares (edição de maio de 2017 do INSS; data base: setembro de 2016).

64 DIAS, Eduardo Rocha; CAMINHA, Uinie. Saúde privada e a Medicina baseada em evidências como fonte de critérios orientadores da intervenção judicial. Direitos Fundamentais \& Justiça, Porto Alegre, v. 31, n. 9, abr. 2015.

65 TIMM, Luciano Benetti. Direito e economia no Brasil. São Paulo: Atlas, 2012, p. 4.

66 BRASIL. Instituto de Estudos de Saúde Suplementar. Variação de custos médicohospitalares. São $2017 . \quad$ Disponível em: <http://documents.scribd.com.s3.amazonaws.com/docs/7t3yiella85w5yu1.pdf>. Acesso em: 28 nov. 2017. 
CAMINHA, Uinie; NORÕES, Mariane. Mercado de saúde suplementar no Brasil e a seleção adversa: uma análise econômica a partir da política de controle de preços dos planos individuais. Revista Eletrônica Direito e Política, Programa de Pós-Graduação Stricto Sensu em Ciência Jurídica da UNIVALI, Itajaí, v.13, n.3, $3^{\circ}$ quadrimestre de 2018. Disponível em: www.univali.br/direitoepolitica - ISSN 1980-7791

Ocorre que, em dezembro de 2016, houve uma queda de 3,5\% nas contratações de planos privados de assistência médico-hospitalar nas faixas etárias de 0 a 18 anos, bem como uma diminuição de 3,4\% nos vínculos contratuais de planos de saúde médico-hospitalares nas faixas etárias de 19 a 58 anos. Ao passo que aumentou em $1,6 \%$ ao ano o vínculo de beneficiários de 59 anos ou mais a planos privados de assistência médico-hospitalar ${ }^{67}$.

A partir desses dados, observa-se que o alto custo dos planos individuais está tornando-os menos atrativo para as pessoas de baixo risco e mais atrativo às pessoas de alto risco. Esse fenômeno é denominado seleção adversa ${ }^{68}$. A tendência é piorar. Pois, segundo dados do IESS, o índice de variação de custos médico-hospitalares para planos individuais atingiu $19,4 \%$ no período de 12 meses terminados em setembro de 2016, em razão da incorporação de procedimentos de alto custo e aumento da frequência anual dos serviços ${ }^{69}$. A ANS, por sua vez, fixou em até $13,55 \%$ o índice de reajuste a ser aplicado aos planos de saúde médico-hospitalares individuais e familiares no período compreendido entre maio de 2017 e abril de $2018^{70}$. Assim, os planos individuais acabam reajustando as suas mensalidades no índice máximo permitido, para repor parte das perdas com a inflação médica, encarecendo cada vez mais as mensalidades dos planos individuais.

Além disso, a projeção da população brasileira por sexo e idade para o período de 2000 a 2060, realizado pelo IBGE71, alerta para um declínio na fecundidade e um aumento da população idosa, acompanhada do aumento na expectativa de

67 BRASIL. Instituto de Estudos de Saúde Suplementar (IESS). Saúde Suplementar em Números. Online.

68 COOTER, Robert; ULEN, Thomas. Direito e economia. Tradução de Luis Marcos Sander, Francisco Araújo da Costa. 5. ed. Porto Alegre: Bookman, 2010.

69 BRASIL. Instituto de Estudos de Saúde Suplementar. Variação de custos médicohospitalares. Online.

70 BRASIL. Agência Nacional de Saúde Suplementar. ANS divulga teto de reajuste autorizado para planos individuais. Disponível em: <http://www.ans.gov.br/aans/noticiasans/consumidor/3907-ans-divulga-teto-de-reajuste-autorizado-para-planos-individuais-2017> . Acesso em: 19 maio 2017.

71 BRASIL. Fundação Instituto Brasileiro de Geografia e Estatística. Projeção da população do Brasil por sexo e idade para o período de 2000 a 2060 . Disponível em: <ftp://ftp.ibge.gov.br/Projecao_da_Populacao/Projecao_da_Populacao_2013/nota_metodologica_2 013.pdf>. Acesso em: 08 jun. $201 \overline{7}$. 
CAMINHA, Uinie; NORÕES, Mariane. Mercado de saúde suplementar no Brasil e a seleção adversa: uma análise econômica a partir da política de controle de preços dos planos individuais. Revista Eletrônica Direito e Política, Programa de Pós-Graduação Stricto Sensu em Ciência Jurídica da UNIVALI, Itajaí, v.13, n.3, $3^{\circ}$ quadrimestre de 2018. Disponível em: www.univali.br/direitoepolitica - ISSN 1980-7791

vida. Hoje, os idosos equivalem à cerca de $10 \%$ da população do Brasil. Em 2050 , a população idosa deverá chegar a $29 \%$ da população brasileira ${ }^{72}$.

É importante o Estado reavaliar o atual modelo de precificação dos planos de saúde, até porque um dos papeis fundamentais do Estado é criar condições para o funcionamento ideal dos mercados ${ }^{73}$. Até o presente momento, o que se verifica na atividade econômica dos planos de saúde é a ostensiva intervenção do Poder Público, impedindo que os planos de saúde criem contratos baseados no risco. Esta intervenção está causando o fenômeno da seleção adversa no mercado de saúde suplementar.

Por conseguinte, a seleção adversa gera alto custo para os planos de saúde. O que se pode esperar se mantida essa política de controle de preços dos planos individuais e familiares é o aumento progressivo das mensalidades, de modo a compensar o desequilíbrio econômico-financeiro causado pela regulação, a falta de interesse das operadoras na comercialização desse tipo de plano, ou, mais grave ainda, o fechamento de inúmeras empresas do setor de saúde suplementar, ao ponto de levar a extinção do mercado de saúde suplementar.

\section{CONSIDERAÇÕES FINAIS}

Diante do exposto, infere-se, inicialmente, que a recessão econômica enfrentada pelo Brasil nos últimos anos afetou negativamente o mercado de saúde suplementar. Outro fator que exerce forte influência na retração do mercado de saúde suplementar e no fenômeno da seleção adversa é a regulamentação do controle de preços dos planos de saúde. Não se ignoram outras externalidades ao contrato de planos de saúde, como as decisões judiciais, que podem afetar a relação contratual e o equilíbrio econômico-financeiro das operadoras de saúde. Todavia, este estudo se deu em relação à política de controle de preços dos planos de saúde individuais e seus efeitos no mercado de saúde suplementar.

\footnotetext{
72 BRASIL. Agência Nacional de Saúde Suplementar. Análise de Nota Técnica Atuarial de Produtos (NTRP) e Pacto Intergeracional. Online.

73 ZYLBERSZTAJN, Décio; SZTAJN, Rachel. Análise econômica do Direito e das Organizações. In: ZYLBERSZTAJN; Décio SZTAJN, Rachel (org.). Direito e economia: análise econômica do direito e das organizações 1.ed. Rio de Janeiro: Campuz, 2005, p. 1-15.
} 
CAMINHA, Uinie; NORÕES, Mariane. Mercado de saúde suplementar no Brasil e a seleção adversa: uma análise econômica a partir da política de controle de preços dos planos individuais. Revista Eletrônica Direito e Política, Programa de Pós-Graduação Stricto Sensu em Ciência Jurídica da UNIVALI, Itajaí, v.13, n.3, $3^{\circ}$ quadrimestre de 2018. Disponível em: www.univali.br/direitoepolitica - ISSN 1980-7791

A regulação e a fiscalização exercida pela Agência Nacional de Saúde Suplementar, apesar de recentes, já têm reflexos na economia. Como visto, a Lei no 9.656/98 determinou expressamente que a idade seria o único critério de cobrança diferenciada de preços, proibindo, assim, às operadoras de criar um contrato em apartado para cada pessoa, segundo o seu risco. Além disso, o Estatuto do Idoso vedou a discriminação ao idoso pelos planos de saúde. Por essa razão, a Resolução Normativa no 63/03 da ANS criou dez faixas etárias de reajustes de preços dos planos de saúde, cujo último reajuste se daria aos 59 anos ou mais e não poderia ultrapassar seis vezes o valor da primeira faixa etária (0 a 18 anos). Este reajuste depende ainda de prévia autorização da ANS e não pode ultrapassar o reajuste máximo previsto pela ANS anualmente, segundo a Resolução Normativa no 171/08.

Portanto, as regras atuais que limitam reajustes de preços dos planos individuais (ou familiares) são as Resoluções Normativas da ANS n 63/03 e n 171/08, as quais permitem que os reajustes sejam estipulados pelas operadoras, de acordo com o custo da saúde e os critérios legais, e também prevê que sejam previamente ratificados pela ANS.

Levando em consideração que os custos de tratamento das pessoas idosas tendem a ser mais elevados do que os custos das pessoas mais jovens, a ANS adotou um modelo de financiamento das operadoras de planos de saúde baseado no mutualismo e na solidariedade intergeracional: o Pacto Intergeracional. Pretendia-se, com este Pacto, oferecer aos indivíduos da mesma faixa etária um valor igual, para que os indivíduos mais saudáveis subsidiassem parte dos gastos dos indivíduos menos saudáveis. O Estado entendeu ainda que os beneficiários das faixas mais jovens deveriam subsidiar parte dos custos dos beneficiários mais idosos. Assim, verificou-se que a ideia deste regime de subsídio cruzado entre gerações é garantir a sustentabilidade do setor de saúde suplementar e proteger o idoso.

Porém, o envelhecimento da população é uma realidade já sentida e que tende a se agravar. Outro evento que se faz sentir é a baixa fecundidade. Isso provoca uma alta de preços em longo prazo, pois, com muitos idosos e poucos jovens, 
CAMINHA, Uinie; NORÕES, Mariane. Mercado de saúde suplementar no Brasil e a seleção adversa: uma análise econômica a partir da política de controle de preços dos planos individuais. Revista Eletrônica Direito e Política, Programa de Pós-Graduação Stricto Sensu em Ciência Jurídica da UNIVALI, Itajaí, v.13, n.3, $3^{\circ}$ quadrimestre de 2018. Disponível em: www.univali.br/direitoepolitica - ISSN 1980-7791

torna o financiamento desse setor insustentável. Por isso, é preciso pensar em soluções sociais e econômicas urgentes, a começar por uma revisão da política de controle de preços dos planos individuais, para que o Estado possa adotar medidas que diminuam os custos de transação desses contratos de planos de saúde e, assim, equilibre economicamente o setor de saúde suplementar.

Do contrário, o elevado valor das mensalidades dos planos de saúde selecionará no mercado somente beneficiário de risco elevado, ao passo que haverá exclusão dos consumidores que têm gastos com saúde inferiores à contraprestação cobrada. A exclusão desses consumidores eleva ainda mais o custo médio das despesas assistenciais, causando a um novo aumento das mensalidades e novas exclusões.

Fato irrefutável hoje é que se tornou quase impossível a contratação de planos de saúde individuais, havendo uma migração para planos empresariais que contam com regulação diversa e mais simples. Esses planos têm admitido um número reduzido de participantes, incentivando consumidores a constituírem pessoas jurídicas para contratá-los.

Portanto, a consequência de tudo isso é um agravamento no bem-estar social, devido à diminuição da eficiência econômica dos planos de saúde. Ou seja, muitos indivíduos serão forçados a abandonar a saúde suplementar e/ou impedidos de ter acesso à saúde privada, inchando, cada vez mais, a precária saúde pública.

O Estado está ciente do problema social e econômico apresentado, por isso, por meio do Poder Legislativo Federal, editou o Projeto de Lei no 7.419/06, que pretende alterar a Lei no 9.656/98 (Lei dos Planos de Saúde) e proteger a manutenção do idoso no mercado de saúde suplementar. Como visto, neste projeto, havia a proposta de parcelamento em cinco vezes e a cada cinco anos do último reajuste por faixa etária. Todavia, cumpre salientar que a referida proposta e a legislação em vigor não impedem que as operadoras de saúde possam repassar as despesas decorrentes da última faixa etária para as faixas anteriores. Então, se fosse aprovada essa regra do Projeto de Lei no 7.419/06 pelas Casas Legislativas, as operadoras de saúde, para amortizar o desequilíbrio 
CAMINHA, Uinie; NORÕES, Mariane. Mercado de saúde suplementar no Brasil e a seleção adversa: uma análise econômica a partir da política de controle de preços dos planos individuais. Revista Eletrônica Direito e Política, Programa de Pós-Graduação Stricto Sensu em Ciência Jurídica da UNIVALI, Itajaí, v.13, n.3, $3^{\circ}$ quadrimestre de 2018. Disponível em: www.univali.br/direitoepolitica - ISSN 1980-7791

econômico-financeiro previsto, poderiam repassar as despesas dos beneficiários com 59 anos ou mais às faixas etárias mais jovens, o que provocaria uma evasão dos consumidores mais jovens do mercado de saúde suplementar, como já se verifica. O que foi até aqui pensado (ou proposto) pelo Estado para a sustentabilidade do setor privado de saúde está longe de resolver o problema da seleção adversa que reclama soluções urgentes.

\section{REFERÊNCIAS DAS FONTES CITADAS}

BARCELLOS, Ana Paula Gonçalves Pereira de et al. Direito à saúde e prioridades: introdução a um debate inevitável. Revista Direito GV, São Paulo, v. 13, n. 2, p. 457-483, maio-ago. 2017. Disponível em: <http://www.scielo.br/pdf/rdgv/v13n2/1808-2432-rdgv-13-02-0457.pdf>. Acesso em: 26 nov. 2017.

BARROS, Pedro Pita. Economia da Saúde: conceitos contemporâneos. 3. ed. Coimbra: Almedina, 2016.

BRASIL. Agência Nacional de Saúde Suplementar. Análise de Nota Técnica Atuarial de Produtos (NTRP) e Pacto Intergeracional. Disponível em: <http://www.ans.gov.br/images/stories/Legislacao/camara_tecnica/analise_ntrp. pdf>. Acesso em: 23 nov. 2017.

BRASIL. Agência Nacional de Saúde Suplementar. ANS divulga teto de reajuste autorizado para planos individuais. Disponível em: <http://www.ans.gov.br/aans/noticias-ans/consumidor/3907-ans-divulga-tetode-reajuste-autorizado-para-planos-individuais-2017>. Acesso em: 19 maio 2017.

BRASIL. Agência Nacional de Saúde Suplementar. Dados e indicadores do setor. Disponível em: <http://www.ans.gov.br/images/stories/Materiais_para_pesquisa/Perfil_setor/Ca derno_informacao_saude_suplementar/2015_mes06_caderno_informacao.pdf > . Acesso em: 27 mar. 2017.

BRASIL. Agência Nacional de Saúde Suplementar. Dados gerais. Disponível em: <http://www.ans.gov.br/perfil-do-setor/dados-gerais>. Acesso em: 09 maio 2017.

BRASIL. Agência Nacional de Saúde Suplementar. Painel de Precificação: plano de saúde 2016. Rio de Janeiro, 2017. Disponível em: <http://www.ans.gov.br/images/stories/Materiais_para_pesquisa/Perfil_setor/Fo co/painel_precificacao2016.pdf>. Acesso em: 23 nov. 2017.

BRASIL. Agência Nacional de Saúde Suplementar. Resolução de Diretoria Colegiada $\mathrm{n}^{\circ} 28$ de 28 de junho de 2000. Altera a RDC n० 4, de 18 de fevereiro de 2000, e institui a Nota Técnica de Registro de Produto. In: Diário Oficial da 
CAMINHA, Uinie; NORÕES, Mariane. Mercado de saúde suplementar no Brasil e a seleção adversa: uma análise econômica a partir da política de controle de preços dos planos individuais. Revista Eletrônica Direito e Política, Programa de Pós-Graduação Stricto Sensu em Ciência Jurídica da UNIVALI, Itajaí, v.13, n.3, $3^{\circ}$ quadrimestre de 2018. Disponível em: www.univali.br/direitoepolitica - ISSN 1980-7791

União, Brasília, DF, 28 jun. 2000. Disponível em: <http://www.ans.gov.br/component/legislacao/?view=legislacao\&task=TextoLei\& format $=$ raw\&id=Mzg3 $>$. Acesso em: 28 nov. 2017.

BRASIL. Agência Nacional de Saúde Suplementar. Resolução de Diretoria Colegiada no 39 de 27 de outubro de 2000. Dispõe sobre a definição, a segmentação e a classificação das Operadoras de Planos de Assistência à Saúde. In: Diário Oficial da União, Brasília, DF, 30 out. 2000. Disponível em: <http://www.ans.gov.br/component/legislacao/?view=legislacao\&task=TextoLei\& format=raw\&id=Mzgw $>$. Acesso em: 28 nov. 2017.

BRASIL. Agência Nacional de Saúde Suplementar. Resolução Normativa no 63 de 22 de dezembro de 2003. Define os limites a serem observados para adoção de variação de preço por faixa etária nos planos privados de assistência à saúde contratados a partir de $1^{0}$ de janeiro de 2004. In: Diário Oficial da União, Brasília, DF, 23 dez. 2003. Disponível em: <http://www.ans.gov.br/component/legislacao/?view=legislacao\&task=TextoLei\& format=raw\&id=NzQ4>. Acesso em: 28 nov. 2017.

BRASIL. Agência Nacional de Saúde Suplementar. Resolução Normativa no 137 de 14 de novembro de 2006. Dispõe sobre as entidades de autogestão no âmbito do sistema de saúde suplementar. In: Diário Oficial da União, Brasília, DF, 20 nov. $2006 . \quad$ Disponível em: <http://www.ans.gov.br/component/legislacao/?view=legislacao\&task=TextoLei\& format $=$ raw\&id $=M T E x N w==>$. Acesso em: 28 nov. 2017.

BRASIL. Agência Nacional de Saúde Suplementar. Resolução Normativa no 171 de 29 de abril de 2008. Estabelece critérios para aplicação de reajuste das contraprestações pecuniárias dos planos privados de assistência suplementar à saúde, médico-hospitalares, com ou sem cobertura odontológica, contratados por pessoas físicas ou jurídicas. In: Diário Oficial da União, Brasília, DF, 30 abr. $2008 . \quad$ Disponível em: <http://www.ans.gov.br/component/legislacao/?view=legislacao\&task=TextoLei\& format $=$ raw\&id $=M T I 4 N A==>$. Acesso em: 17 nov. 2017.

BRASIL. Agência Nacional de Saúde Suplementar. Resolução Normativa no 183 de 19 de dezembro de 2008. Altera a Resolução de Diretoria Colegiada - RDC No 28, de 26 de junho de 2000, que dispõe sobre a Nota Técnica de Registro de Produto e dá outras providências. In: Diário Oficial da União, Brasília, DF, 22 dez. 2008. Disponível em: < http://www.ans.gov.br/component/legislacao/?view=legislacao\&task=TextoLei\&f ormat $=$ raw\&id $=M T M 30 A==>$. Acesso em: 28 nov. 2017.

BRASIL. Agência Nacional de Saúde Suplementar. Resolução Normativa no 191 de 08 de maio de 2009. Institui o Fundo Garantidor do Segmento de Saúde Suplementar (FGS) pelas Operadoras de Planos de Saúde. In: Diário Oficial da União, Brasília, DF, 13 maio 2009. Disponível em: <http://www.ans.gov.br/component/legislacao/?view=legislacao\&task=TextoLei\& format $=$ raw\&id=MTQyNQ==>. Acesso em: 17 nov. 2017. 
CAMINHA, Uinie; NORÕES, Mariane. Mercado de saúde suplementar no Brasil e a seleção adversa: uma análise econômica a partir da política de controle de preços dos planos individuais. Revista Eletrônica Direito e Política, Programa de Pós-Graduação Stricto Sensu em Ciência Jurídica da UNIVALI, Itajaí, v.13, n.3, $3^{\circ}$ quadrimestre de 2018. Disponível em: www.univali.br/direitoepolitica - ISSN 1980-7791

BRASIL. Agência Nacional de Saúde Suplementar. Resolução Normativa no 195 de 14 de julho de 2009. Dispõe sobre a classificação e características dos planos privados de assistência à saúde, regulamenta a sua contratação, institui a orientação para contratação de planos privados de assistência à saúde e dá outras providências. In: Diário Oficial da União, Brasília, DF, 15 jul. 2009. Disponível em: <http://www.ans.gov.br/component/legislacao/?view=legislacao\&task=TextoLei\& format $=$ raw\&id $=M T Q 10 A==>$. Acesso em: 07 mar. 2018.

BRASIL. Agência Nacional de Saúde Suplementar. Resolução Normativa no 196 de 14 de julho de 2009. Dispõe sobre a Administradora de Benefícios. In: Diário Oficial da União, Brasília, DF, 19 jul. 2009. Disponível em: <http://www.ans.gov.br/component/legislacao/?view=legislacao\&task=TextoLei\& format $=$ raw\&id $=M T Q 10 Q==>$. Acesso em: 27 nov. 2017.

BRASIL. Agência Nacional de Saúde Suplementar. Resolução Normativa no 252 de 28 de abril de 2011. Dispõe sobre as regras de portabilidade e de portabilidade especial de carências, alterando as Resoluções Normativas no 186, de 14 de janeiro de 2009, e no 124, de 30 de março de 2006, e a Resolução de Diretoria Colegiada no 28 , de 26 de junho de 2000. In: Diário Oficial da União, Brasília, DF, 29 abril. 2009. Disponível em: <http://www.ans.gov.br/component/legislacao/?view=legislacao\&task=TextoLei\& format $=$ raw\&id $=M T c y O A==>$. Acesso em: 28 nov. 2017.

BRASIL. Agência Nacional de Saúde Suplementar. Resolução Normativa no 304 de 19 de setembro de 2012. Dispõe sobre o encaminhamento da Nota Técnica de Registro de Produtos - NTRP para planos coletivos empresariais e altera a Resolução da Diretoria Colegiada -RDC no 28, de 26 de junho de 2000. In: Diário Oficial da União, Brasília, DF, 20 set. 2012. Disponível em: <http://www.ans.gov.br/component/legislacao/?view=legislacao\&task=TextoLei\& format $=$ raw\&id $=$ MjIzOA $==>$. Acesso em: 28 nov. 2017.

BRASIL. Agência Nacional de Saúde Suplementar. Sala de situação. Disponível em: <http://www.ans.gov.br/perfil-do-setor/dados-e-indicadores-do-setor/salade-situacao>. Acesso em: 07 mar. 2018.

BRASIL. Câmara dos Deputados. Comissão Especial destinada a proferir parecer ao projeto de Lei $\mathrm{n}^{\circ} \mathbf{7 . 4 1 9}$, de 2006, do Senado Federal, que "altera a Lei no 9.656, de 3 de junho de 1998, que dispõe sobre os planos e seguros privados de assistência à saúde", e apensados. Disponível em: <http://www2.camara.leg.br/atividadelegislativa/comissoes/comissoes-temporarias/especiais/55a-legislatura/pl-741906-planos-de-saude/documentos/outros-documentos/parecer-do-relator-08-112017>. Acesso em: 07 dez. 2017.

BRASIL. Câmara dos Deputados. Confira as propostas para mudanças nas regras dos planos de saúde. Disponível em: <http://www2.camara.leg.br/camaranoticias/noticias/SAUDE/547584-CONFIRAAS-PROPOSTAS-PARA-MUDANCA-NAS-REGRAS-DOS-PLANOS-DE-SAUDE. html>. Acesso em: 26 nov. 2017. 
CAMINHA, Uinie; NORÕES, Mariane. Mercado de saúde suplementar no Brasil e a seleção adversa: uma análise econômica a partir da política de controle de preços dos planos individuais. Revista Eletrônica Direito e Política, Programa de Pós-Graduação Stricto Sensu em Ciência Jurídica da UNIVALI, Itajaí, v.13, n.3, $3^{\circ}$ quadrimestre de 2018. Disponível em: www.univali.br/direitoepolitica - ISSN 1980-7791

BRASIL, Câmara dos Deputados. Planos de saúde: mudança no texto adia votação do relatório. Disponível em: <http://www2.camara.leg.br/camaranoticias/noticias/SAUDE/549945-PLANOSDE-SAUDE-MUDANCA-NO-TEXTO-ADIA-VOTACAO-DO-RELATORIO.html >. Acesso em: 08 dez. 2017.

BRASIL. Conselho de Saúde Suplementar. Resolução no 6 de 16 de 03 novembro de 1998. Dispõe sobre critérios e parâmetros de variação das faixas etárias dos consumidores para efeito de cobrança diferenciada, bem como de limite máximo de variação de valores entre as faixas etárias definidas para planos e seguros de assistência à saúde. In: Diário Oficial da União, Brasília, DF, 04 nov. 1998. Disponível em: <http://www.ans.gov.br/component/legislacao/?view=legislacao\&task=TextoLei\& format=raw\&id=NTg5> . Acesso em: 27 nov. 2017.

BRASIL. Constituição da República Federativa do Brasil. Brasília: Senado Federal, $1988 . \quad$ Disponível em: <http://www.planalto.gov.br/ccivil_03/constituicao/constituicaocompilado.htm>. Acesso em: 25 out. 2017.

BRASIL. Decreto-Lei no 73 de 21 de novembro de 1966. Dispõe sobre o Sistema Nacional de Seguros Privados, regula as operações de seguros e resseguros e dá outras providências. In: Diário Oficial da República Federativa do Brasil, Brasília, DF, 21 nov. 1966.2 Disponível em: <http://www.planalto.gov.br/ccivil_03/decreto-lei/Del0073.htm>. Acesso em: 27 nov. 2017.

BRASIL. Fundação Instituto Brasileiro de Geografia e Estatística. Pesquisa Nacional por Amostra de Domicílios Contínua Primeiro trimestre de 2017. Disponível em: <ftp://ftp.ibge.gov.br/Trabalho_e_Rendimento/Pesquisa_Nacional_por_Amostra_ de_Domicilios_continua/Trimestral/Fasciculos_Indicadores_IBGE/pnadc_201701_ trimestre_caderno.pdf> Acesso em: 08 jun. 2017.

BRASIL. Fundação Instituto Brasileiro de Geografia e Estatística. Projeção da população do Brasil por sexo e idade para o período de 2000 a 2060. Disponível em: <ftp://ftp.ibge.gov.br/Projecao_da_Populacao/Projecao_da_Populacao_2013/not a_metodologica_2013.pdf>. Acesso em: 08 jun. 2017.

BRASIL. Fundação Instituto de Pesquisas Contábeis, Atuariais e Financeiras. Parecer Técnico: Diferenciação de Risco e Mensalidade ou Prêmio entre Faixas Etárias em Planos e Seguros de Saúde. São Paulo, ago./2009. Disponível em: <http://www.fipecafi.org/downloads/newsletter/faixaetariaparecertecnicoatuarial .pdf>. Acesso em: 23 nov. 2017.

BRASIL. Instituto de Estudos de Saúde Suplementar. Determinantes da posse de plano de saúde. Disponível em: <http://documents.scribd.com.s3.amazonaws.com/docs/5rs5h3epmo5tl5h3.pdf> . Acesso em: 11 maio 2017. 
CAMINHA, Uinie; NORÕES, Mariane. Mercado de saúde suplementar no Brasil e a seleção adversa: uma análise econômica a partir da política de controle de preços dos planos individuais. Revista Eletrônica Direito e Política, Programa de Pós-Graduação Stricto Sensu em Ciência Jurídica da UNIVALI, Itajaí, v.13, n.3, $3^{\circ}$ quadrimestre de 2018. Disponível em: www.univali.br/direitoepolitica - ISSN 1980-7791

BRASIL. Instituto de Estudos de Saúde Suplementar. Saúde Suplementar em Números. Disponível em: <http://documents.scribd.com.s3.amazonaws.com/docs/7pydrps16o5rf6n0.pdf> . Acesso em: 08 jun. 2017.

BRASIL. Instituto de Estudos de Saúde Suplementar. Variação de custos médico-hospitalares. São Paulo, 2017. Disponível em: <http://documents.scribd.com.s3.amazonaws.com/docs/7t3yiella85w5yu1.pdf>. Acesso em: 28 nov. 2017.

BRASIL. Lei no 5.764 de 16 de dezembro de 1971. Define a Política Nacional de Cooperativismo, institui o regime jurídico das sociedades cooperativas, e dá outras providências. In: Diário Oficial da República Federativa do Brasil, Brasília, DF, 16 dez. 1971. Disponível em: <http://www.planalto.gov.br/ccivil_03/leis/L5764.htm>. Acesso em: 28 nov. 2017.

BRASIL. Lei no 8.078 de 11 de setembro de 1990. Dispõe sobre a proteção do consumidor e dá outras providências. In: Diário Oficial da República Federativa do Brasil, Brasília, DF, 12 set. 1990. Disponível em: <http://www.planalto.gov.br/ccivil_03/leis/L8078.htm> Acesso em: 16 nov. 2017.

BRASIL. Lei no 8.080 de 19 de setembro de 1990. Dispõe sobre as condições para a promoção, proteção e recuperação da saúde, a organização e o funcionamento dos serviços correspondentes e dá outras providências. In: Diário Oficial da República Federativa do Brasil, Brasília, DF, 19 set. 1990. Disponível em: <http://www.planalto.gov.br/ccivil_03/leis/l8080.htm>. Acesso em: 27 nov. 2017.

BRASIL. Lei no 9.656 de 03 de junho de 1998. Dispõe sobre os planos e seguros privados de assistência à saúde. In: Diário Oficial da República Federativa do Brasil, Brasília, DF, 03 jun. 1998. Disponível em: <http://www.planalto.gov.br/ccivil_03/leis/L9656.htm>. Acesso em: 27 nov. 2017.

BRASIL. Lei no 9.961 de 28 de janeiro de 2000. Cria a Agência Nacional de Saúde Suplementar - ANS e dá outras providências. In: Diário Oficial da República Federativa do Brasil, Brasília, DF, 28 jan. 2000. Disponível em: <http://www.planalto.gov.br/ccivil_03/leis/L9961.htm>. Acesso em: 27 nov. 2017.

BRASIL. Lei no 10.185 de 12 de fevereiro de 2001. Dispõe sobre a especialização das sociedades seguradoras em planos privados de assistência à saúde e dá outras providências. In: Diário Oficial da República Federativa do Brasil, Brasília, DF, 12 fev. $2001 . \quad$ Disponível em: <http://www.planalto.gov.br/ccivil_03/leis/leis_2001/l10185.htm>. Acesso em: 07 fev. 2018. 
CAMINHA, Uinie; NORÕES, Mariane. Mercado de saúde suplementar no Brasil e a seleção adversa: uma análise econômica a partir da política de controle de preços dos planos individuais. Revista Eletrônica Direito e Política, Programa de Pós-Graduação Stricto Sensu em Ciência Jurídica da UNIVALI, Itajaí, v.13, n.3, $3^{\circ}$ quadrimestre de 2018. Disponível em: www.univali.br/direitoepolitica - ISSN 1980-7791

BRASIL. Lei no 10.741 de $1^{\circ}$ de outubro de 2003. Dispõe sobre o Estatuto do Idoso e dá outras providências. In: Diário Oficial da República Federativa do Brasil, Brasília, DF, 12 fev. 2001. Disponível em: <http://www.planalto.gov.br/ccivil_03/leis/2003/L10.741.htm>. Acesso em: 28 nov. 2017.

CECHIN, José. Saúde na idade - por que diferenciar preços de planos de saúde por idade e consequências econômicas da não aplicação dos reajustes previstos em contrato. IN: NOBRE, Milton Augusto de Brito; SILVA, Ricardo Augusto Dias da (org.). O CNJ e os desafios da efetivação do direito à saúde. Belo Horizonte: Fórum, 2011, p. 149-170.

COOTER, Robert; ULEN, Thomas. Direito e economia. Tradução de Luis Marcos Sander, Francisco Araújo da Costa. 5. ed. Porto Alegre: Bookman, 2010.

COASE, Ronald Harry. A firma, o mercado e o direito. Tradução de Heloisa Gonçalves Barbosa. Rio de Janeiro: Forense Universitária, 2016.

CUNHA JÚNIOR, Luiz Arnaldo Pereira da. O mercado de saúde suplementar - a busca do equilíbrio. IN: NOBRE, Milton Augusto de Brito; SILVA, Ricardo Augusto Dias da (org.). $\mathbf{O}$ CNJ e os desafios da efetivação do direito à saúde. Belo Horizonte: Fórum, 2011, p. 273-301.

DI PIETRO, Maria Sylvia Zanella. Direito Administrativo. 26. ed. São Paulo: Atlas, 2013.

DIAS, Eduardo Rocha; CAMINHA, Uinie. Saúde privada e a Medicina baseada em evidências como fonte de critérios orientadores da intervenção judicial. Direitos Fundamentais \& Justiça, Porto Alegre, v. 31, n. 9, abr. 2015.

GOMES, Josiane Araújo. Contratos de Planos de Saúde: a busca judicial pelo equilíbrio de interesses entre os usuários e as operadoras de planos de saúde. Leme (SP): JH Mizuno, 2016.

GRAU, Eros Roberto. A ordem econômica na Constituição de 1988. 12. ed. São Paulo: Malheiros, 2007.

GONÇALVES, Sandra Krieger. Judicialização do direito à saúde e o sistema de saúde suplementar no Brasil: aspectos críticos da fundamentação de decisões judiciais. Rio de Janeiro: Lumen Juris, 2016.

MATA, Beatriz Resende Rios da. Impacto Financeiro de 2010 a 2030 do envelhecimento dos beneficiários em operadoras de planos de saúde de Minas Gerais: um estudo de caso. 2011. 148f. Dissertação (Mestrado). Centro de Desenvolvimento e Planejamento Regional, Universidade Federal de Minas Gerais, Belo Horizonte. 2011.

SANTOS, Lenir. A natureza jurídica pública dos serviços de saúde e o regime de complementaridade dos serviços privados à rede pública do Sistema Único de Saúde. Saúde debate, Rio de Janeiro, v. 39, n. 106, p. 815-829, jul-set, 2015. 
CAMINHA, Uinie; NORÕES, Mariane. Mercado de saúde suplementar no Brasil e a seleção adversa: uma análise econômica a partir da política de controle de preços dos planos individuais. Revista Eletrônica Direito e Política, Programa de Pós-Graduação Stricto Sensu em Ciência Jurídica da UNIVALI, Itajaí, v.13, n.3, $3^{\circ}$ quadrimestre de 2018. Disponível em: www.univali.br/direitoepolitica - ISSN 1980-7791

Disponível em: <http://www.scielo.br/pdf/sdeb/v39n106/0103-1104-sdeb-39106-00815.pdf>. Acesso em: 26 nov. 2017.

SAMPAIO, Aurisvaldo. Contratos de Plano de Saúde: regime jurídico e proteção do sujeito mais fraco das relações de consumo. (Biblioteca de Direito do Consumidor, v. 40). São Paulo: Revista dos Tribunais, 2010.

SARLET, Ingo Wolgang; SAAVEDRA, Giovani Agostini. Judicialização, reserva do possível e compliance na área da saúde. Revista de Direitos e Garantias Fundamentais, Vitória, v. 18, n. 1, p. 257-282, jan./abr. 2017.

TIMM, Luciano Benetti. Direito e economia no Brasil. São Paulo: Atlas, 2012.

ZYLBERSZTAJN, Décio; SZTAJN, Rachel. Análise econômica do Direito e das Organizações. In: ZYLBERSZTAJN; Décio SZTAJN, Rachel (org.). Direito e economia: análise econômica do direito e das organizações 1.ed. Rio de Janeiro: Campuz, 2005, p. 1-15.

Recebido em: 06/06/2018

Aprovado em: 10/11/2018 